\title{
EL DERECHO A LA PRIVACIDAD EN LA JURISDICCIÓN DE PROTECCIÓN
}

\author{
THE RIGHT TO PRIVACY UNDER THE JURISDICTION OF THE \\ ACTION FOR PROTECTION
}

\section{Rodolfo Figueroa G.}

\begin{abstract}
RESUMEN: En Chile existe una extensa literatura referida al derecho a la privacidad, pero escasean los trabajos destinados a identificar categorías de privacidad y a sistematizar la jurisprudencia recaída sobre ese derecho, con excepción de cuatro autores nacionales que han intentado sistematizar la jurisprudencia. El presente trabajo sugiere continuar con ese esfuerzo de sistematización, recurriendo a la taxonomía de privacidad propuesta por Solove, un autor que distingue 16 categorías de privacidad. Así, este trabajo presenta de manera resumida la jurisprudencia de privacidad producida bajo la jurisdicción de protección en Chile, sistematizada conforme esas 16 categorías. Se verá que en Chile hay recursos de protección en 13 de esas 16 categorías.
\end{abstract}

Palabras clave: Privacidad, sistematización, recurso de protección.

ABSTRACT: There is abundant literature in Chile regarding the right to privacy, but there are scarce papers devoted to identify categories of privacy and to systematize the jurisprudence produced upon such a right, with the exception of four Chilean authors who have attempted to systematize the jurisprudence. This paper proposes to continue that effort of systematization, applying the taxonomy of privacy suggested by Solove, an author that distinguishes 16 categories of privacy. Thus, this paper presents a summary of the jurisprudence elaborated through the jurisdiction of protection, systematized according to those 16 categories. We will see that we have cases for 13 of those 16 categories.

Key words: Privacy, Taxonomy, Action for Protection.

\section{INTRODUCCIÓN}

Este artículo presenta lo que ha señalado la jurisprudencia de protección en materia del derecho a la vida privada. Esta jurisprudencia se sistematiza según ciertas categorías de privacidad que nunca se han utilizado en nuestro medio. No se abarca la jurisprudencia producida en otras jurisdicciones, como en sede laboral o del Tribunal Constitucional, asunto que se reserva para otra oportunidad. Los fallos revisados comprenden el período entre 1981 y el año $2012^{1}$.

* Licenciado en Ciencias Jurídicas y Sociales. Universidad Diego Portales. Abogado. Master of Laws (LL.M) y Doctor of Juridical Science (S.J.D) University of Wisconsin. rodolfo.figueroa@udp.cl. Profesor Investigador, Director del Departamento de Derecho Público y Director del Magíster en Derecho Público, Escuela de Derecho, Universidad Diego Portales. Este artículo es parte de una investigación asociada al Proyecto Fondecyt No 11090351. En este trabajo y en la investigación Fondecyt recibí la valiosa colaboración de Francisco J. Cañas, ayudante de derecho constitucional de la Escuela de Derecho de la Universidad Diego Portales.

${ }^{1}$ Las bases de datos utilizadas son: la Revista de Derecho y Jurisprudencia, la Gaceta Jurídica y la revista Fallos del Mes, desde 1981 hasta el último número disponible. Además, se revisaron las bases de datos electrónicos Mi- 
En Chile existe abundante literatura sobre el derecho a la vida privada, que intenta precisar en qué consiste este derecho: es entendido como intimidad, en el sentido de conciencia; como el derecho a estar solo, esto es, apartado de observación (lo que podemos llamar seclusión ${ }^{2}$ o tranquilidad); como secreto; como un ámbito de no injerencia; como autodeterminación y autonomía; como el derecho a restringir información sobre uno mismo; como territorialidad, lo que comprende seclusión y secreto, y también como un derecho a la imagen. Es evidente que algunas de estas nociones se superponen o implican entre sí. Sin embargo, es posible afirmar que dicha literatura no se ha dedicado a sistematizar las categorías o ámbitos que estarían comprendidos por el derecho a la privacidad ni tampoco a sistematizar la jurisprudencia producida con ocasión de dicho derecho. Algunos autores nacionales aluden por vía ejemplar a ciertos casos de la jurisprudencia chilena y comparada, pero no encontramos una sistematización de la jurisprudencia constitucional sobre el derecho a la vida privada, con excepción de cuatro autores nacionales. Revisar esos cuatro intentos y sus debilidades permite apreciar la necesidad y utilidad de buscar una nueva forma de categorizar la jurisprudencia chilena, tal como ofrece más adelante en este trabajo.

1.1. Rodríguez ordena la jurisprudencia en seis grupos: 1. Información comercial (casos contra Dicom o el Boletín Comercial). 2. Propia imagen, cuerpo y nombre (publicaciones de fotografías en diarios, la rectoscopía en la Clínica Alemana y reportajes de televisión). 3. Edificaciones en altura. 4. Medidas disciplinarias (entidades que han aplicado sanción a socio o miembro). 5. Inviolabilidad de documentos privados. 6. Vida privada y libertad de expresión (casos contra medios de comunicación o publicaciones) ${ }^{3}$.

Revisemos brevemente esta sistematización. Como se puede apreciar, los grupos $1 \mathrm{y}$ 5 se refieren a documentos privados, de modo que se superponen. El grupo 4 se refiere a sanciones, pero es dudoso que se trate de una dimensión de la privacidad; más bien puede ser honra. El grupo 6 no corresponde a una categoría porque narra casos de colisión entre el derecho a la vida privada y la libertad de expresión. El grupo 2 engloba varios aspectos del derecho a la vida privada que es conveniente separar, como veremos más adelante. Finalmente, el grupo 3 tampoco corresponde a una categoría de privacidad sino un hecho que vulnera una dimensión de la privacidad, como sería el derecho a ser dejado tranquilo. Revisemos ahora un segundo autor.

1.2. Gómez ordena la jurisprudencia de privacidad en 13 acápites: 1. Uso o divulgación de información íntima (secreto profesional). 2. El derecho a la imagen, que comprende: a) Derecho a la imagen en lugares públicos (publicaciones en la prensa). b) Derecho a la imagen en lugares privados (rectoscopía). c) Apropiación y uso publicitario de la imagen (casos de publicidad con imagen ajena). d) Imagen y honra (casos de publicidad de una municipalidad y publicaciones en internet). e) Derecho a la imagen y acciones colectivas

croiuris, LegalPublishing y West Law tal como estaba constituidas entre el año 2010 y el 2012. Finalmente, se revisaron bases de datos físicas de fallos en poder de particulares. La muestra que se constituyó comprende cerca de 350 casos.

2 Del inglés seclusion. Barros utiliza este anglicismo y propongo incorporarlo. Ver Barros (1998).

3 Rodríguez (1999) pp. 719-744. 
(caso Hijos de Putre). f) Derecho a la imagen en establecimientos educacionales (colegios que regulan vestimenta de alumnos). 3. Divulgación de aspectos, o situaciones de la vida privada por medios de comunicación (reportajes de revistas y televisión). 4. Afectación de la vida privada y el derecho a la honra (casos Martorell, Ultima Tentación de Cristo y Prat). 5. Exigencia del Estado a particulares de proveer información privada (casos contra el SII). 6. Divulgación de información que atenta contra la privacidad y la honra (amenazas de divulgar información). 7. Derecho a la vida privada y divulgación de información económica o financiera, que comprende: a) La obtención, almacenamiento y divulgación de información económica por instituciones financieras, Superintendencias y por Dicom. b) Divulgación de información en entidades particulares. c) Divulgación pública de información personal incorrecta. 8. El derecho a la vida privada como espacio visual (edificaciones en altura). 9. Minorías sexuales (procedimiento policial contra homosexual). 10. El derecho a la vida privada como autonomía (esterilización de una persona deficiente mental). 11 . Discriminación basada en comportamientos privados (casos de estudiantes embarazadas). 12. Casos de violación del hogar, que comprende: a) Casos de inmuebles, restituciones y arrendamientos, b) Impedimentos para ingresar a hogares, c) Mala vecindad y d) Descerrajamientos. 13. Inviolabilidad de toda forma de comunicación privada ${ }^{4}$.

Comentarios sobre esta sistematización: a) Los grupos 1, 3, 4, 5, 6 y 7 tienen que ver con uso o divulgación de información personal (sea íntima, comercial, etc.). Por tanto, no hace mucho sentido distinguirlas sin recurrir a otras categorizaciones, como se hará más adelante. b) El grupo 2 comprende varios subgrupos de divulgación de imágenes y no se trata de una categoría de privacidad. Todos esos subgrupos habría que ubicarlos en distintas categorías del derecho a la privacidad. c) Los grupos 3 y 4 no se distinguen realmente pues ambos consisten en divulgar algo. d) El grupo 6 alude tanto a la privacidad como a la honra, de modo que no es una categoría separada. Además, la amenaza de divulgación y la divulgación misma no son dos categorías distintas de privacidad'. e) El grupo 7 engloba tanto la recolección de información y el procesamiento como la divulgación, que son categorías diferentes, según veremos más adelante Por eso, sería útil distinguirlas. f) Los grupos 9 y 11 no son categorías de privacidad. g) Los grupos 12 y 13 corresponden a una sola categoría, que es la invasión de la privacidad, de modo que no es necesario distinguirlas. h) Los grupos 8 y 10 sí parecen ser categorías distintivas de la privacidad. Pasemos ahora a un tercer autor.

1.3 Anguita presenta una sistematización de la privacidad en 8 grupos: 1. Derecho a la propia imagen, que comprende: a) Derecho a la propia imagen y vida privada (publicaciones no autorizadas de fotos en la prensa). b) Derecho a la Propia Imagen y Falsa Apariencia (publicaciones que distorsionan la imagen de una persona). c) Derecho a la Propia Imagen y Valor Comercial. 2. Vida privada y principio de la autonomía de la persona (casos de colegios que regulan la apariencia personal de los alumnos). 3. Intimidad corporal (rectoscopía de la Clínica Alemana.) 4. La inviolabilidad de toda forma de comunicaciones

\footnotetext{
4 Gómez (2005) 665 p. Ver pp. 322-419.

5 Solove sugiere colocar a la amenaza en un lugar separado, pero eso lo hace porque distingue varias formas de divulgación, de modo que en su esquema sí se justifica la separación, como veremos más adelante.
} 
privadas. 5. Cámaras ocultas y derecho a la vida privada. 6. Derecho a la vida privada vs. libertad de emitir opinión y de informar (casos de libros o reportajes sobre asuntos que los recurrentes consideran parte de su vida privada). 7 . Libertad de informar de los medios de comunicación social sobre casos pendientes de resolución en los Tribunales de Justicia (programas de televisión o reportajes sobre sucesos que están sometidos a la jurisdicción). 8. Derecho a la protección de la vida privada y datos personales (Dicom) ${ }^{6}$.

Comentarios sobre esta sistematización: a) Las categorías 5, 6 y 7 no son categorías de privacidad. b) Las categorías 1, 3 y 4 comprenden a diversas hipótesis de captación que es necesario separar. c) Las categorías 4 y 8 se refieren ambas a información privada. No tiene sentido distinguirlas, a menos que se haga a partir de un criterio más específico, que no se proporciona. d) En cambio, sí es apropiado distinguir derecho a la propia imagen, autonomía e intimidad corporal.

Finalmente, veamos una cuarta sistematización de la privacidad.

Tapia distingue 2 grandes categorías de privacidad: 1. Apropiación: que comprende 3 subcategorías: a) Casos de irrupción en el domicilio (incluye edificación en altura). b) Casos de correspondencia y comunicaciones. c) Casos de explotación de atributos de la persona, como nombre, imagen y voz. 2. Divulgación: comprende 5 subcategorías: a) Información biológica (Registro Nacional de ADN). b) Convicciones de la persona (no se citan casos ocurridos en Chile). c) Vida afectiva y familiar (diario de vida del cónyuge). d) Historia y hábitos (alude a revelaciones sobre el pasado del individuo). e) Antecedentes comerciales ${ }^{7}$.

Observaciones sobre esta sistematización: a) El profesor Tapia ordena los casos en torno a dos criterios centrales, captación y divulgación. Este es un avance importante en la sistematización de la jurisprudencia. Sin embargo, la captación es denominada apropiación por el profesor Tapia y eso genera un error sistemático, como veremos luego. b) En la categoría 1.b) tenemos captación de información privada (leer correos privados) en tanto en la categoría 1.c) tenemos divulgación de la imagen de alguien en un medio de prensa. Una es captación y la otra es apropiación, de modo que no pueden estar ambas en el mismo grupo. c) La categoría 2.a) incluye el caso de $\mathrm{ADN}$, que es captación o registro, más que divulgación, de modo que no debe estar en este grupo. El otro caso que se menciona es la rectoscopía, que tampoco es divulgación sino captación. d) Las categorías 2.b) 2.c) y 2.d) podrían coincidir si se pretende revelar un hecho de la vida privada que sea afectivo y constituya un hábito. Por tanto, es mejor no considerar las tres categorías distintas o separarlas con algún criterio más específico. e) La categoría 2.e) debería ser parte de un grupo mayor, de revelación de información privada, con independencia del contenido de lo revelado.

En resumen, tenemos cuatro intentos de sistematizar la jurisprudencia de privacidad. Sin embargo, adolecen de problemas: algunas categorías que se presentan como diferentes en verdad no lo son; otras no son categorías de privacidad; algunas agrupan situaciones que habría que distinguir y, finalmente, se echa de menos una muy importante categoría de privacidad que es el procesamiento. Un autor la menciona, pero no la usa como categoría. La doctrina chilena más bien parece distinguir 2 grandes dimensiones de la privacidad: la

\footnotetext{
${ }^{6}$ Anguita (2006) pp. 319-521.

7 TAPIA (2008) pp. 117-144.
} 
captación y la divulgación. Pero falta la categoría de procesamiento, que tiene que ver con todo el tema de las bases de datos. Finalmente, la doctrina chilena identifica la categoría de autonomía, pero no sabe dónde colocarla.

Por estas razones, el resto de este trabajo está dedicado a presentar la jurisprudencia de privacidad en sede de protección, pero sistematizada conforme un esquema un poco más extenso y complejo que el que hemos visto hasta ahora.

\section{SISTEMATIZACIÓN DE LA JURISPRUDENCIA DE PROTECCIÓN SOBRE EL DERECHO A LA PRIVACIDAD}

En esta parte presentaremos la jurisprudencia de protección recaída sobre el derecho a la privacidad. Lo importante es la sistematización de dicha jurisprudencia. Para efectuar dicha sistematización, no se empleará ninguna noción de privacidad específica porque eso produciría una distorsión en la identificación de los casos, dejando fuera los que no calcen con la noción. Sí se tendrá como base las ideas de privacidad que la doctrina chilena ha señalado y que se reseñaron más atrás, pero sobre todo, se sistematizará la jurisprudencia a partir de las categorías que menciona Solove ${ }^{8}$. Este autor anglosajón distingue 4 dimensiones de la privacidad, las que albergan en total de 16 categorías de privacidad, harto más que lo que ha identificado la doctrina chilena. Lo interesante es que en Chile podemos hallar casos para 13 de esas 16 categorías, lo que hace pertinente y útil emplear el esquema de Solove ${ }^{9}$. A continuación, se señalarán las categorías respectivas y se aludirá a algunos de los casos que es posible incluir en ellas.

\subsection{Recolección de información. Esta dimensión consiste en la CAPTACIÓN DE INFORMACIÓN Y COMPRENDE DOS CATEGORÍAS: VIGILANCIA E INTERROGACIÓN}

2.1.1. Vigilancia. Conforme esta categoría, la privacidad se ve afectada por actos de vigilancia. En Chile se han producido varios casos que podrían corresponden a esta categoría y se pueden separar en dos grupos: i) vigilancia mediante cámaras de televisión (o CCTV) y ii) otras formas de vigilancia.

i) Los casos de CCTV a su vez se pueden clasificar en: a) cámaras instaladas en buses, b) en la empresa y c) en un colegio.

a) Tratándose de cámaras de televisión instaladas en buses, los recurrentes son los microbuseros (solo en un caso son los trabajadores) que accionan contra la Inspección del Trabajo, por haberles cursado multas por diversos conceptos, entre ellos, por la instalación de las referidas cámaras. La Inspección del Trabajo sostiene que dichas cámaras vulneran el derecho a la integridad y la honra del trabajador. La jurisprudencia

\footnotetext{
8 Solove (2006) pp. 478-564 y Solove (2009) 257 pp.

9 Un autor nacional que conoce parte de la tradición anglosajona (por ejemplo, a Prosser) en categorías de privacidad es Corral. Corral (2000). Este autor identifica cinco categorías de privacidad: intromisión, difusión, utilización, distorsión y decisión (p. 343). Sin embargo, él estima que solo las dos primeras categorías tienen que ver con privacidad, las demás no. 345-346.
} 
en esta materia a nivel de las Cortes de Apelaciones no es uniforme: a veces se protege a los trabajadores y a veces no. Sin embargo, la Corte Suprema validó el uso de las cámaras como una medida de seguridad y de control de la actividad de los choferes ${ }^{10}$. b) En el caso de cámaras de monitoreo instaladas al interior del recinto de una empresa o lugar de trabajo, la situación no es distinta. Los recurrentes son los trabajadores, que estiman que un sistema de vigilancia permanente vulnera el derecho a la vida privada, la dignidad, la honra o la salud mental. Hay varios fallos en los cuales las Cortes de Apelaciones rechazan los recursos, apoyando funciones de seguridad de las cámaras y de protección del proceso productivo. Esta doctrina está confirmada por la Corte Suprema, que ha declarado expresamente que las cámaras pueden ser utilizadas por las empresas siempre que se encuentre contemplado en el reglamento interno, que los trabajadores tomen conocimiento de ello y que se emplee este sistema únicamente para funciones de seguridad y protección ${ }^{11}$. Esta doctrina es respaldada en otro fallo de la Corte Suprema, en el cual se señala que la instalación de cámaras en las áreas de producción de la empresa no lesiona derechos constitucionales ${ }^{12}$. Sin embargo, este último fallo tiene dos votos disidentes que suscriben la tesis de que un sistema de monitoreo permanente del comportamiento de los trabajadores vulnera su intimidad, su derecho a la honra y la vida privada ${ }^{13}$.

c) Existe un caso de una cámara oculta instalada en un colegio. Se recurre en contra del alcalde de la Municipalidad de El Bosque y del Canal de Televisión de la U. Católica por la existencia de cámaras de televisión ocultas en pasillos, patios y salas de clase del Liceo Juan Gómez Millas, que se instalaron luego de acontecimientos de violencia ocurridos dentro del colegio. La Corte de Apelaciones rechazó el recurso y apoyó las cámaras ocultas por las siguientes consideraciones: i) Las cámaras fueron instaladas con autorización del director del establecimiento; ii) La finalidad fue mejorar la protección de los propios alumnos, ante hechos de violencia serios que se habían producido; iii) Se adoptaron medidas de resguardo de la privacidad, como la prohibición de divulgación de las grabaciones sin autorización del director; iv) Los lugares donde estaban emplazadas las cámaras, si bien no eran lugares públicos, eran espacios abiertos donde normalmente no se esperaba que existiera privacidad; v) El uso de cámaras ocultas se justifica debido a episodios graves de violencia ocurridos en el colegio, algunos de carácter delictivo. La corte estima que el interés público supera al privado. Además, las cámaras no graban sonidos, lo que no afecta la privacidad de las comunicaciones ${ }^{14}$.

ii) Otras formas de vigilancia. Veremos tres casos:

a) Revisión de una carta privada al ingresar a la cárcel. Se recurre en contra de gendarmería por haber revisado la carta. La corte apoya al establecimiento penitenciario,

\footnotetext{
10 Bart Vega con Inspección Provincial del Trabajo IX Región (2009).

11 Vásquez Torres con Empresas Aqua Chile (2006).

12 Sociedad Industrial y Comercial Salucorp LTDA con Dirección del Trabajo Santiago Oriente (2009).

13 Sociedad Industrial y Comercial Salucorp LTDA con Dirección del Trabajo Santiago Oriente (2009).

14 Phillips Salinas con Alcalde de la Municipalidad de El Bosque (2002).
} 
señalando que se trata de una medida de seguridad mínima y que no es desproporcionada ${ }^{15}$.

b) Los miembros del sindicato de trabajadores No 1 del Banco de Chile recurren contra esa entidad por instaurar una nueva modalidad de seguro de salud complementario, que exige entregar información sobre el diagnóstico del paciente, primeros síntomas, tratamiento indicado, entre otros. El banco implementó esta medida para fiscalizar abusos en el cobro de los beneficios. La Corte de Apelaciones acoge el recurso, estimando que las exigencias del nuevo formulario violan la confidencialidad de la relación médico-paciente ${ }^{16}$. Sin embargo, la Corte Suprema revoca la sentencia por dos consideraciones: i) La ley de datos personales señala expresamente que puede haber acceso a datos de salud cuando sean necesarios para la determinación u otorgamiento de beneficios de salud a los titulares; ii) El banco implementó esta política para poder controlar el explosivo aumento de los gastos generados por este beneficio de salud ${ }^{17}$.

c) Una empresa tiene como política que los trabajadores dependientes y aquellos que no tengan cargos directivos sean revisados al abandonar las dependencias de la empresa. El control consiste en un examen visual de carteras, bolsos, mochilas o paquetes. La Inspección Comunal del Trabajo cursó multas a esta empresa por emplear medidas de revisión y control que atentan contra la dignidad y la honra de las personas. La empresa recurre en contra de estas multas. La Corte de Apelaciones de Valparaíso acoge el recurso indicando que la fiscalizadora se había arrogado facultades jurisdiccionales al valorar la medida de control incluida en el reglamento de la empresa, actuando fuera del ámbito de su competencia y lesionando el patrimonio de la empresa ${ }^{18}$. Sin embargo, hubo un voto disidente que estuvo por rechazar el recurso. En cambio, la Corte Suprema rechaza el recurso de la empresa, estimando que las medidas de revisión lesionan la honra de los trabajadores y su dignidad ${ }^{19}$.

2.1.2. Interrogación. En esta categoría, la privacidad se vulnera cuando una persona es sometida a un interrogatorio que le exige revelar datos sobre sí mismo. En esta categoría se identificó un solo caso en Chile. Además, es discutible que el caso en cuestión corresponda exactamente a esta categoría. Un juez de garantía acoge la petición de la Defensoría Penal Pública de someter a un examen de veracidad a dos menores de edad, víctimas del delito de violación. Como este examen ya se había practicado con anterioridad, el Sename estima que la petición es injustificada porque victimiza nuevamente a los niños, atentando contra su integridad psíquica. Se recurre en contra de la orden del juez. La Corte de Apelaciones rechaza el recurso considerando que la petición no es arbitraria porque está de acuerdo con el principio de objetividad que regula el proceso penal ${ }^{20}$. La Corte Suprema confirma la decisión ${ }^{21}$.

15 Fuentes Castro con Alcaide Centro Penitenciario Punta de Peuco (2007).

16 Sindicato de Trabajadores $N^{\circ} 1$ del Banco de Chile S.A. con Banco de Chile S.A. (2004).

17 Sindicato de Trabajadores $N^{\circ} 1$ del Banco de Chile S.A. con Banco de Chile S.A. (2004).

18 Valparaiso Stores Co. S.A. con Inspección Comunal del Trabajo de Valparaíso (2009).

19 Valparaíso Stores Co. S.A. con Inspección Comunal del Trabajo de Valparaíso (2009).

20 Sename con Juez del Juzgado de Garantía de Talca (2005).

${ }^{21}$ Sename con Juez del Juzgado de Garantía de Talca (2005). 


\subsection{Procesamiento de información.}

La privacidad no solo se puede vulnerar por recolección de información o divulgación, sino también en una serie de casos que Solove engloba en esta categoría de procesamiento, que tiene que ver con el uso, almacenamiento y manipulación de información que ya ha sido recolectada ${ }^{22}$, normalmente en bases de datos. Como se dijo antes, esta categoría está ausente en la doctrina nacional, lo que no resulta comprensible atendido que esta materia se encuentra regulada en Chile por la ley de datos personales ${ }^{23}$. En efecto, el artículo 3 de la ley regula la identificación y alude a lo que Solove denomina uso secundario y apropiación ${ }^{24}$; los artículos 4, 5 y 9 claramente prohíben el uso secundario ${ }^{25}$; el artículo 6 alude a lo que Solove llama exclusión ${ }^{26}$ y el artículo 11 regula el problema atingente a la categoría denominada inseguridad ${ }^{27}$. Además, el artículo 3 alude a la recolección de datos, que corresponde a la dimensión de Recolección.

Pues bien, esta dimensión de procesamiento incluye 5 categorías $^{28}$ :

2.2.1. Agregación. La agregación consiste en conectar diversas partes aisladas de información para construir un perfil identificable de una persona ${ }^{29}$. Sin embargo, no se encontraron en Chile casos que pudieran corresponden a esta categoría.

2.2.2. Identificación. La identificación consiste en conectar información que existe en alguna base de datos o registro con una persona en particula ${ }^{30}$. No se han encontrado casos en Chile que correspondan exactamente a esa hipótesis pero hemos decidido incluir en esta categoría aquellos casos relativos al registro que contempla la ley sobre Registro Nacional de ADN porque son los que más se acercan a ella. Se trata de casos relativos a adolescentes infractores de la ley penal, respecto de los cuales se ha solicitado su incorporación en el Registro Nacional de ADN, conforme al procedimiento previsto en la ley No 19.970. En todos los casos, un defensor penal público deduce recurso de protección en favor de los

\footnotetext{
22 Solove (2009) p. 117.

${ }^{23}$ Ley No 19.628.

${ }^{24}$ Art. $3^{\circ}$. "En toda recolección de datos personales que se realice a través de encuestas, estudios de mercado o sondeos de opinión pública u otros instrumentos semejantes, sin perjuicio de los demás derechos y obligaciones que esta ley regula, se deberá informar a las personas del carácter obligatorio o facultativo de las respuestas y el propósito para el cual se está solicitando la información. La comunicación de sus resultados debe omitir las señas que puedan permitir la identificación de las personas consultadas".

${ }^{25}$ Art. 4. Inc. 20: "La persona que autoriza debe ser debidamente informada respecto del propósito del almacenamiento de sus datos personales y su posible comunicación al público". Art. 5 inc. 4: "El receptor solo puede utilizar los datos personales para los fines que motivaron la transmisión". Art. 9 inc. 10: "Los datos personales deben utilizarse solo para los fines para los cuales hubieren sido recolectados, salvo que provengan o se hayan recolectado de fuentes accesibles al público".

${ }^{26}$ Art. $6^{\circ}$. "Los datos personales deberán ser eliminados o cancelados cuando su almacenamiento carezca de fundamento legal o cuando hayan caducado.

Han de ser modificados cuando sean erróneos, inexactos, equívocos o incompletos".

27 Art. 11. "El responsable de los registros o bases donde se almacenen datos personales con posterioridad a su recolección deberá cuidar de ellos con la debida diligencia, haciéndose responsable de los daños".

${ }^{28}$ Ley de Datos Personales recoge 4 de las 5 categorías comprendidas en esta dimensión.

29 Solove (2009) p. 118.

30 Solove (2009) p. 122.
} 
menores, sancionados en conformidad a la ley penal adolescente. El recurso se interpone en contra del Sename, del Servicio Médico Legal o de ambos, por haber decretado que se aplique a los jóvenes infractores el procedimiento de registro de ADN.

La mayoría de los casos han sido rechazados por las Cortes de Apelaciones, en atención a que: i) La huella genética solo permite identificar a un individuo, pero no proporciona información adicional de carácter físico o psíquico de la persona; ii) La ley dispone que la información es reservada y no puede utilizarse para vulnerar la privacidad de los individuos. iii) La ley dispone la obligación de reserva de parte de quienes pueden tener acceso a ella y establece sanciones para la divulgación o uso de la información.

Sin embargo, el año 2009 hubo un caso en Santiago que fue acogido. La Corte de Santiago señaló que la ley de registro afecta la integración social del adolescente e infringe el principio del interés superior del niño. La razón de ello es que la incorporación de las huellas genéticas en el registro de condenados es de por vida ${ }^{31}$. Esto afectaría el derecho a la vida privada y la honra ${ }^{32}$. Ahora bien, esta sentencia fue revocada por la Corte Suprema, señalando que el registro no infringe el derecho a la privacidad pues de la huella no pueden desprenderse características físicas o psíquicas del individuo. Además, la ley dispone un sistema de reserva de la información, limitando el acceso y sancionando su uso indebido ${ }^{33}$. Existe un voto disidente del ministro Brito, que señala que el registro vulnera la privacidad y honra porque la inclusión en él es para toda la vida. Esto afecta, además, la reinserción del adolescente. Por otra parte, aunque haya obligación de reserva, igual se vulneran los derechos del artículo 19 el no 4 porque el registro se aplica sobre datos privados que cada persona tiene bajo su dominio.

2.2.3. Inseguridad. Esta categoría alude al temor que el titular tiene acerca de la protección que recaiga sobre información almacenada en alguna base de datos, que le pertenez$\mathrm{ca}^{34}$. En esta categoría se encontraron dos casos. En el primero, la Compañía de Teléfonos de Chile (CTC) recurre en contra del Subsecretario de Telecomunicaciones, en nombre propio y de sus clientes, por una resolución que autoriza la entrega de los datos de individualización completa de los suscritores de servicio telefónico a los portadores de larga distancia para que estos pudieran cobrar a los usuarios por el servicio. La Corte de Apelaciones rechaza la acción estimando que la individualización completa del suscriptor y su entrega a un tercero no constituyen una amenaza al derecho a la vida privada. La razón de ello es que resulta necesario presumir por parte de los portadores de larga distancia un uso racional y justo de la información obtenida ${ }^{35}$. El fallo fue confirmado por la Corte Suprema.

Otro caso de inseguridad se produce en el Hospital Base de Valdivia, que instala un nuevo sistema de control de asistencia, consistente en un reloj biométrico que es de uso obligatorio por parte de los funcionarios. Este reloj está conectado a una ficha personal

\footnotetext{
31 Retamales Saldias y otros con Sename (2009) Co 8.

32 Retamales Saldias y otros con Sename (2009) $C^{\circ} 10$.

33 Retamales Saldias y otros con Sename (2009).

34 Solove (2009) p. 127.

35 CTC con Subsecretario de Telecomunicaciones (1995) Co3.
} 
digital que contiene los datos personales de los funcionarios, almacenada en una base de datos administrada por el departamento de recursos humanos del referido hospital. Un médico solicitó su eliminación por estimar que el sistema no garantizaba la inviolabilidad de la información personal. Su petición fue desechada. El director del hospital solicitó un pronunciamiento a la Contraloría Regional y lo mismo hizo la Asociación de Funcionarios del Hospital. El órgano contralor validó el sistema de control biométrico. La Asociación de Funcionarios recurre de protección en contra del dictamen por estimar que vulnera el derecho a la vida privada. El daño a la privacidad estaría dado por la inseguridad del sistema de almacenamiento y el riesgo de uso malicioso de la información por parte de terceros que pudieren acceder a ella. La Corte de Apelaciones rechaza el recurso por estimar que la exigencia de utilizar una clave de acceso y la huella dactilar para acceder a la ficha personal constituyen mecanismos de seguridad suficientes de la confidencialidad de la información ${ }^{36}$ La sentencia fue confirmada por la Corte Suprema.

2.2.4. Uso secundario. Esta categoría consiste en emplear información privada para un fin distinto de aquel para el cual fue obtenida ${ }^{37}$. Esta categoría está presente en muchos casos de recursos de protección. Sin embargo, en casi todos ellos, además de dañarse la privacidad como uso secundario, se daña también la privacidad en otras categorías. Cuando eso ocurre, se procede a identificar aquella categoría en la cual el daño es mayor, para incluir en ella el caso y explicarlo. Eso ha producido que en esta parte casi no se relaten casos pues siempre el daño es mayor en otra categoría. Sin perjuicio de ello, podemos relatar aquí el caso de aquella persona que consintió en que le tomaran una fotografía porque se le dijo que era para un proyecto personal, pero esa foto fue utilizada por el Ministerio de Obras Públicas para promocionar obras viales mediante gigantografías, que exhiben la imagen del afectado. El recurrente señala que no ha dado su consentimiento para que se utilice su imagen con fines propagandísticos del gobierno. La Corte de Apelaciones acoge el recurso debido a que el recurrente no autorizó al MOP para que utilizara su imagen con fines publicitarios. Añade que esta conducta vulnera el derecho de propiedad sobre la imagen. Además, la corte señala que si bien hubo autorización para captar la imagen, no la hubo para el uso que se dio a ella con posterioridad ${ }^{38}$. Sin embargo, la Corte Suprema revoca la sentencia por dos consideraciones: i) Hubo autorización de parte del afectado de ser fotografiado ${ }^{39}$; ii) No se perturba la vida privada porque en la foto el afectado aparece en un lugar tomando locomoción, que es una actividad que cualquier ciudadano hace a diario, con un paisaje de fondo, sin que se pueda vislumbrar qué actividades está realizando ${ }^{40}$.

2.2.5. Exclusión. Esta categoría de privacidad consiste en la facultad del titular de poder acceder a, corregir y/o eliminar información personal que exista en algún registro o

\footnotetext{
36 Asociación de Funcionarios del Hospital Base de Valdivia con Contralor de la Región de Los Lagos (2006) C०6.

37 Solove (2009) p. 131.

38 Salazar Leiva con MOP (2009) $\mathrm{C}^{\circ} 10$.

39 Salazar Leiva con MOP (2009) $\mathrm{C}^{\circ} 6$.

40 Salazar Leiva con MOP (2009) C 8.
} 
base de datos ${ }^{41}$. En esta categoría se han producido cientos de casos en Chile, todos los cuales consisten en peticiones de eliminar o excluir de un registro información comercial del afectado. Por una parte, existen muchos casos en contra de la Tesorería General de la República o Tesorerías Regionales por revelar a Dicom deudas tributarias de los contribuyentes. Hubo algunos casos rechazados pero desde el año 2006 los casos son acogidos de manera mayoritaria por las Cortes de Apelaciones y de manera uniforme por la Corte Suprema. El argumento es que la conducta de la Tesorería infringe el artículo 17 de la ley No 19.628: las deudas tributarias no se pueden informar.

Por otra parte, hay muchos casos contra Dicom/Equifax, con la misma petición. En estos casos, los derechos invocados han sido la vida privada y/o la honra y/o el derecho de propiedad. Las cortes, cuando han acogido las acciones, lo han hecho por honra, por privacidad y por propiedad. Las cortes han decidido de la siguiente forma: i) Cuando la deuda sí existe, o es de aquellas que la ley autoriza a informar, se rechaza el recurso. ii) Cuando no existe anotación en el boletín, no existe el protesto, la deuda es discutible, la deuda no existe, la deuda ya fue pagada o el afectado no suscribió el pagaré, acogen los casos por honra. iii) Cuando la deuda no estaba acreditada, no existe la deuda, existe error en el envío de información, la información no debió publicarse por exceder el plazo, o se informa deuda que no está permitido informar, los casos se acogen por privacidad. Se puede advertir que se repite una causal. Además, en algunos de estos casos las cortes acogen las acciones tanto por honra como por privacidad simultáneamente. Finalmente, un caso implica a Chilecompras y chileproveedores y se resolvió de la misma manera ${ }^{42}$.

\subsection{DiseminaCión DE INFORMACIÓN}

Esta categoría de la privacidad consiste, en general, en la divulgación de información privada, y es la que normalmente produce mayor daño a este derecho. Solove identifica 7 categorías de divulgación:

2.3.1. Quiebre de confidencialidad. Esta categoría consiste en la revelación de información privada por parte de quien la recibió bajo secreto profesional ${ }^{43}$. En esta categoría es posible separar los casos en tres grupos:

a) Casos en que se pide a profesionales que revelen información confidencial de sus clientes o pacientes. Hay dos casos en que un médico recurre de protección en contra de Fonasa porque ha dispuesto que un funcionario del servicio, que no es médico, ejecute labores de fiscalización, entre las cuales pueda acceder a las fichas clínicas de los pacientes de los médicos sometidos al control de Fonasa, con la finalidad de verificar la procedencia

\footnotetext{
41 Solove (2009) 133-4.

42 En estos casos hubo revelación de información a un tercero ¿Por qué incluirlos en esta categoría de Excusión? La razón es el daño a la privacidad que se produce por existir información en un registro y por eso, la petición del afectado consiste en eliminar esa información del registro. De hecho, cuando los casos se ganan, las cortes ordenan la eliminación del registro. Sin embargo, en los casos contra Tesorería, la información no se elimina del registro y las cortes ordenan a Tesorería no informar, aunque la información recibida por Dicom debe ser eliminada de sus registros.

43 Solove (2009) p. 137.
} 
de las prestaciones de salud practicadas. En uno de ellos, la Corte de Apelaciones rechaza el recurso, estimando que el deber de reserva lo tiene cualquier funcionario público, en virtud de las normas del estatuto administrativo y las normas del Código Penal aplicables a los funcionarios públicos. La corte estima que no es necesario ser médico para estar sometido al deber de reserva ${ }^{44}$. La Corte Suprema confirma la sentencia, con dos votos disidentes, según los cuales la confidencialidad de la ficha clínica exige que si alguien la ve, sea un médico. Los disidentes argumentan que el paciente le confía información privada y personalísima al médico ${ }^{45}$ en atención a su profesión, que comprende el deber del secreto profesional $^{46}$. La reserva de la ficha solo se puede asegurar de manera efectiva mediante la intervención de un médico ${ }^{47}$. En el otro caso, la Corte de Apelaciones acoge la acción, considerando que la conducta de Fonasa obliga al médico a ejecutar un acto impropio, que viola el secreto profesional y daña el ámbito íntimo del paciente ${ }^{48}$. No se apeló ante la Corte Suprema.

b) Casos en que se solicita a una institución bancaria la revelación de información sobre cuentas corrientes y operaciones financieras de sus clientes. La situación se produce porque un tercero solicita acceso a información bancaria, que está protegida por el secreto bancario, y la entidad requerida se niega a proporcionar esa información, invocando dicho secreto. Estos son casos de confidencialidad porque el cliente confía en que la institución guardará la debida reserva de la información privada, tal como exige la ley. Ahora bien, la ley autoriza el acceso a información bancaria en casos que se esté investigando un delito. Las cortes han resuelto estos casos de manera uniforme: cuando la petición se ajusta estrictamente a la ley, es posible revelar la información bancaria; de lo contrario, se acoge el recurso y se niega el acceso a la información.

c) Casos que pueden implicar algún grado de confidencialidad entre cónyuges. Se han producido dos casos. En uno de ellos, un cónyuge presenta en un juicio de divorcio un diario de vida del otro cónyuge, sin su autorización ${ }^{49}$. En otro, un cónyuge presenta correos electrónicos del otro cónyuge, también en juicio por divorcio y sin su autorización ${ }^{50}$. En ambos casos, las cortes rechazaron los recursos. Es discutible que estos casos correspondan a hipótesis de confidencialidad pues es discutible que entre cónyuges exista ese deber. Lo interesante es que las cortes no desecharon completamente que pudiera haber algún deber de reserva. El problema en los dos casos explicados es que las piezas o instrumentos privados ya fueron agregados a un expediente conforme las normas que reglan el procedimiento, de modo que las cortes, conociendo del recurso, se han negado a entrometerse en el proceso seguido ante otro tribunal.

\footnotetext{
44 Troncoso Huerta con Fondo Nacional de Salud Antofagasta (1986) C 7-8.

45 Troncoso Huerta con Fondo Nacional de Salud Antofagasta (1986) C 10.

46 Troncoso Huerta con Fondo Nacional de Salud Antofagasta (1986) Co 9.

7 Troncoso Huerta con Fondo Nacional de Salud Antofagasta (1986) C 11.

48 Caro Marambio con Fondo Nacional de Salud Valparaíso (2005) C 3 y 8.

49 Muller Pasmiño con Babaic Bartulovic (2006).

50 Anguita Ramírez con Juez Titular del Familia de Viña del Mar (2008).
} 
2.3.2. Revelación. Esta categoría de la privacidad consiste en revelar o divulgar a terceros información privada verdadera de una persona. En esta categoría existen pocos casos en Chile. En uno de ellos, la recurrente es alumna de la Universidad Uniacc. Esta entidad le impide hacer la práctica profesional y titularse, decisión que adoptó al enterarse de una resolución dictada por la Comisión de Medicina Preventiva que certifica la incapacidad de la recurrente para trabajar como psicóloga. La Universidad Uniacc se enteró de esta incapacidad porque la Universidad Católica se lo comunicó. A su vez, la Universidad Católica se enteró de ello porque la recurrente le había solicitado la condonación de una deuda, para lo cual la alumna proporcionó a la Universidad Católica el referido certificado de incapacidad. La recurrente interpone la acción en contra de la Universidad Uniacc, alegando violación de la ley sobre datos privados. La corte desestima el recurso. En primer lugar, señala que el documento recibido por la Uniacc fue remitido por la UC de manera voluntaria. En segundo lugar, sostiene que esa información no se ha proporcionado a terceros ${ }^{51}$.

Otro ejemplo podría corresponder al conocido caso Luksic con Martorell. El empresario recurre de protección en contra de un periodista por intentar publicar en Chile un libro en el cual aparecería implicado. En el libro se narran hechos vergonzosos de extorsión sexual protagonizados por el ex embajador de Argentina en Chile, aunque en el recurso no se precisa la relación entre esos hechos y el recurrente. En todo caso, el recurrente señala que los hechos descritos en el libro son falsos y denigrantes. La corte acoge el recurso y prohíbe la publicación del libro. Cabe señalar que no queda claro en este caso si los hechos son verdaderos o falsos, lo que es importante para efectos de determinar la categoría de privacidad afectada: si los hechos fuesen falsos, el señor Luksic sería puesto bajo una luz falsa ante los demás afectándose su derecho a la privacidad como falsa luz. En cambio, si los hechos fuesen verdaderos, se afectaría la privacidad como revelación. Cabe señalar que en ambas hipótesis también se daña su honra.

La corte señala que los hechos de la vida privada e íntima no se pueden divulgar a terceros y agrega que lo íntimo no es susceptible de ser expuesto a la sociedad sin consentimiento del afectado ${ }^{52}$. Además, la corte alude a un afán de morbosidad. Estas declaraciones dejan entrever que los hechos no se consideran falsos o deformados. Por tanto, este sería un caso de privacidad como revelación. La Corte Suprema confirma la sentencia y reconoce que en este caso está involucrada la vida privada, además de la honra y la dignidad de la persona ${ }^{53}$.

2.3.3. Exposición. Esta categoría consiste en mostrar el cuerpo de una persona contra su voluntad en términos tales que la avergüenza, humilla o denigra. Por ejemplo, publicar fotos de una persona desnuda ${ }^{54}$. En esta categoría se encontraron dos casos en Chile. En el primero, el señor Bohme recurre en contra de la Clínica Alemana porque cuando se practicaba un examen de rectoscopía a su madre, una empresa externa filmó el procedi-

\footnotetext{
51 Aguilar Cáceres con UNIACC (2007) C $C^{\circ}$. Sentencia confirmada por la Corte Suprema.

52 Luksic Craig con Martorell Camarella (1993) C 8.

53 Luksic Craig con Martorell Camarella (1993) C 3.

54 Solove (2009) p. 147.
} 
miento sin su autorización. Estima que se vulnera el derecho a la vida privada, al hacer denigrante un examen que de por sí ya es agraviante. La Clínica Alemana señala que entre sus funciones está la docencia y la filmación de procedimientos le permite efectuar cursos de capacitación. Añade que hubo un consentimiento tácito de la paciente. Además, durante la práctica del examen, la paciente estaba cubierta, siendo imposible ver su rostro o identificarla, tampoco saber su sexo; también estaba cubierto el resto de su cuerpo, excepto aquella parte sobre la cual debía efectuarse la rectoscopía. La corte acoge el recurso, desestimando el argumento de que la paciente estaba cubierta o no era reconocible. La corte declara que conforme a los cánones culturales dominantes ciertas partes del cuerpo humano, entre ellas aquella que fue objeto de la filmación, no deben ni pueden exhibirse a menos que la propia persona implicada lo autorice de modo expreso ${ }^{55}$. Por tanto, la corte declara que se vulnera el derecho a la privacidad ${ }^{56}$.

El otro caso corresponde a alumnos de un colegio que fueron desnudados como parte de un procedimiento de investigación, incoado por el robo de un celular al interior del establecimiento. En el procedimiento intervino personal de Carabineros. Los hombres fueron separados de las mujeres, llevados a dependencias separadas y quedaron los hombres solo en calzoncillos y las niñas desnudas de la cintura para arriba, solo en sostenes. La Corte de Apelaciones acoge el recurso. Estima que se vulnera el ámbito íntimo de los alumnos y la dignidad inherente a toda persona ${ }^{57}$. Sin embargo, la corte acoge el recurso por el $n^{0} 4$ del artículo 19, sin distinguir privacidad de honra; de hecho, la corte no utiliza la palabra privacidad. La Corte Suprema rechaza la acción, porque las medidas de reparación ya se habían adoptado.

2.3.4. Accesibilidad aumentada. Esta categoría de privacidad consiste en acrecentar el acceso para terceros de información privada que tiene un grado reducido de publicidad; por ejemplo, se encuentra en un registro público pero poca gente la conoce. Se diferencia de la categoría de revelación porque en ese caso la información no se conocía. El daño se produce al titular porque alguien toma esa información y acrecienta el acceso a ella para muchas personas ${ }^{58}$. En esta categoría se hallaron varios casos.

a) Una mujer recurre en contra de una escritora que pretende escribir una novela sobre los hijos de detenidos desaparecidos en Chile que fueron adoptados cuando sus padres desaparecieron. La recurrente es hija adoptiva, que se enteró hace poco tiempo que su madre biológica fue detenida y desaparecida y su padre ejecutado político. La escritora tiene la intención de incluir la historia de la recurrente en su novela. La recurrente estima que revelar su historia personal afecta su derecho a la vida privada, su honra y su dignidad. La corte rechaza el recurso. En primer lugar, porque estima que en general, los acontecimientos que constituyen la base de la novela son de público conocimiento ${ }^{59}$. Segundo, porque no existe

\footnotetext{
55 Bohme Bascuñán con Clínica Alemana (1992) C C $^{\circ}$. Sentencia confirmada por la Corte Suprema.

56 Bohme Bascuñán con Clínica Alemana (1992) C $\mathrm{C}^{\circ} 8$.

57 Narváez Muñoz con Director de Liceo Politécnico C-40 Villarrica (2009) C 7.

58 Solove (2009) p. 150.

59 Callejas Leiva con Echeverría Yáñez (2000) C⒈
} 
arbitrariedad ni ilegalidad en el acto de escribir una novela ${ }^{60}$. Tercero, porque ponderando el derecho a la intimidad y la libertad de expresión, en este caso, primaría la libertad de expresión $^{61}$. Cuarto, porque no se advierte en la novela el daño a los derechos que la recurrente reclama ${ }^{62}$. La Corte Suprema confirma la sentencia.

b) La revista Caras desea realizar un reportaje sobre la muerte del señor Zegers, quien se habría suicidado como consecuencia de la muerte de su hija en un accidente de avión en Arequipa. Su esposa recurre en contra de la referida revista, para que el reportaje no salga a la luz. Impugna la conexión entre el suicidio y el accidente y agrega que el reportaje causará un daño a sus hijas, que son menores de edad. Invoca su derecho a la vida privada. La revista se defiende señalando que el accidente aéreo y el suicidio del señor Zegers fueron cubiertos por la prensa en su minuto de manera profusa de modo que no existe intimidad sino interés público en tales acontecimientos. La Corte de Apelaciones acoge el recurso por varias consideraciones, una de las cuales consiste en accesibilidad aumentada. En efecto, la corte señala que se debe evitar que se acreciente el dolor ya producido a la familia ${ }^{63}$, lo que se produciría por la publicación del reportaje. La nueva publicación acrecentaría la accesibilidad de los hechos y eso acrecentaría el dolor ya producido. La corte está consciente de que acoger el recurso implica censurar la libertad de expresión, pero estima que la vida privada prima en este caso ${ }^{64}$. La Corte Suprema, en cambio, lo rechaza por no advertir ilegalidad ni arbitrariedad ${ }^{65}$.

c) Un abogado envía una carta al Regimiento de Infantería, lugar donde trabaja el recurrente, en la cual revela que el recurrente tiene una hija no reconocida y que será sometido a un juicio de reconocimiento de paternidad. Copia de esa carta fue también enviada al Comandante del Regimiento y al Director del Personal del Ejército. El recurrente afirma que esta conducta le causa serias molestias y pone en peligro su permanencia en el Ejército, vulnerando las garantías señaladas en el artículo $19 \mathrm{~N}^{\text {os }} 4$ y 24. La corte rechaza el recurso, estimando que "...si bien un litigio puede hacer derivar algunas informaciones que sean perjudiciales para alguna parte, está por encima de eso el derecho de los ciudadanos de pedir protección a los Tribunales de Justicia" ${ }^{66}$.

d) Televisión Nacional de Chile desea hacer un programa sobre el asesinato de un abogado e incendio de su oficina para ocultar el crimen. Los hijos y su madre recurren en contra del programa, invocando el derecho a la vida privada y la honra. La corte rechaza el recurso, señalando que el recurrente invoca solamente el honor, el cual no se ve afectado por el hecho de informar la verdad de lo ocurrido ${ }^{67}$. La sentencia es confirmada por la Corte Suprema.

${ }^{60}$ Callejas Leiva con Echeverría Yáñez (2000) C $\mathrm{C}^{\circ} 4$.

${ }^{61}$ Callejas Leiva con Echeverría Yáñez (2000) C $\mathrm{C}^{\circ} 2$.

${ }^{62}$ Callejas Leiva con Echeverría Yánez (2000) $\mathrm{C}^{\circ} 3$.

${ }^{63}$ Donoso Arteaga con Revista Caras (1998) C 6.

${ }^{64}$ Donoso Arteaga con Revista Caras (1998) C ${ }^{\circ} 6$.

${ }^{65}$ Donoso Arteaga con Revista Caras (1998).

${ }^{66}$ Ferrer Lagunas con Levi (1993) $\mathrm{C}^{\circ} 1$.

67 Torres Hevia con TVN (2003). 
e) Una mujer reclama en contra de la Corporación Administrativa del Poder Judicial porque en su sitio web es posible advertir que la actora está involucrada en un proceso de reclamación de paternidad de su hija. Este le permite a cualquier persona enterarse de que tiene una hija no reconocida, que es un dato de su vida privada. La corte rechaza la acción. El argumento es que el sitio web no da información sobre el proceso, ni sobre el contenido de las resoluciones, y porque la información que sí da es la misma que cualquier persona puede obtener revisando los libros de ingreso o las notificaciones del estado diario ${ }^{68}$. La sentencia es confirmada por la Corte Suprema.

f) La fiscalía solicita al Tribunal Penal de Coyhaique que una audiencia sea pública y que se permita a los medios de comunicación filmar y efectuar publicaciones con nombre y apellido de los imputados. El tribunal accede a la solicitud, pero con la limitación de que no se filme los rostros de los acusados ni difunda sus nombres salvo las identidades de las personas que en ese momento estén en el lugar de los acusados. El fundamento de esta limitación es proteger el honor, privacidad, dignidad de los acusados y la presunción de inocencia. Un periodista, en representación suya y del colegio de periodistas, recurre de protección en contra de los jueces. La corte determina que los jueces no pueden impedir que se filme el rostro de los imputados ni que se revelen sus nombres, apoyando esa medida en un derecho a la privacidad ${ }^{69}$.

2.3.5. Chantaje. Esta categoría consiste en amenazar a alguien con la revelación de información privada. En esta categoría no se encontraron casos de recursos de protección en Chile.

2.3.6. Apropiación. Esta categoría consiste en la utilización de la imagen o identidad de un tercero para fines propios. En esta categoría existen muchos casos en Chile, que se pueden separar en tres grupos:

i) Publicación de fotos en diarios sin autorización. Existen varios casos contra diarios por la publicación no autorizada de una foto del afectado. a) El primer caso involucra al diario La Cuarta por haber publicado en dos oportunidades la foto de una mujer, tomada en la playa, vistiendo traje de baño, acompañada la foto con una leyenda típica de ese diario. No hubo autorización ni para tomar la foto ni para publicarla. Se reclama por el respeto y protección de la vida privada y pública y a la honra de la persona y su familia. La Corte de Apelaciones rechaza el recurso por dos consideraciones. Primero, porque las empresas periodísticas adquieren el derecho de publicar las fotos que obtengan las personas que trabajen para ellas, de suerte que la publicación de las fotos no constituye un acto arbitrario o ilegal ${ }^{70}$. Segundo, porque una playa es un lugar público. Por tanto, una persona no está protegida por el derecho a la privacidad en dicho lugar ${ }^{71}$.

\footnotetext{
68 Briceño Echeverría con Corporación Administrativa del Poder Judicial (2001) C $\mathrm{C}^{\circ}$ 3-5.

69 Vizcarra Ramirez con Jueces del Tribunal Oral en lo penal de Coyhaique (2004) Co 4.

70 Alvarado Solari con Diario La Cuarta (1989) C $C^{\circ} 5$.

${ }^{71}$ Alvarado Solari con Diario La Cuarta (1989) C $C^{\circ}$.
} 
Después de este caso, se producen varios más, en los cuales las cortes cambian su doctrina. En uno de ellos, la corte sostiene que las fotografías publicadas en un diario con esa reputación ( La Cuarta) dañan la dignidad de la joven, su honra y su vida privada ${ }^{72}$. Además, la aparición de la foto de una persona en un diario sin autorización vulnera su derecho a la vida privada ${ }^{73}$. En otro caso contra el mismo diario, la corte rechaza la idea de que se dañe la honra, pero reconoce el derecho a la imagen ${ }^{74}$ y dispone expresamente que en lugares públicos sí existe un derecho a la privacidad que significa el derecho a no ser fotografiado sin autorización y no ser publicado en un diario ${ }^{75}$. En otro caso, la corte señala que si la persona no es identificable en la foto, no se vulnera el derecho a la imagen ${ }^{76}$. Esta decisión fue confirmada por la Corte Suprema.

ii) Publicación de imagen en internet. Una foto fue subida a internet sin autorización de la persona que aparece en ella, unida a ciertos comentarios denigrantes. La Corte de Apelaciones acoge el recurso señalando que la fotografía y los textos añadidos a ella son injuriosos y lesivos de la honra, fama e imagen de la recurrente, lesionando los derechos contenidos en el artículo 19 no 1,4 y $24^{77}$. La sentencia es confirmada por la Corte Suprema.

iii) Publicidad no consentida con imagen del afectado. Existen varios casos en contra de empresas que efectuaron publicidad de sus productos utilizando la imagen de alguna persona destacada o conocida, sin su autorización y sin compensación económica. En un primer caso, la corte no proporciona protección: un grupo de futbolistas recurre en contra de la empresa Salo por comercializar un álbum de figuras, atingentes a futbolistas chilenos, incluidos los recurrentes, sin su autorización, y empleando su imagen, nombre y fama para perseguir fines lucrativos, vulnerando los derechos reconocidos en el $n^{\circ} 4$, vida privada y honra, y 24 del artículo 19. La Corte de Apelaciones rechaza la acción ${ }^{78}$ y la Corte Suprema confirma la decisión estimando que no se vulnera ningún derecho constitucional. Primero, porque no se utiliza la imagen de los recurrentes ya que el álbum tiene espacios en blanco ${ }^{79}$. Segundo, porque al señalar datos físicos de cada futbolista no se daña su vida privada ${ }^{80}$. Tercero, porque la publicidad no daña su honra ${ }^{81}$. Cuarto, porque el derecho de propiedad no comprende todos los derechos, como el derecho al nombre ${ }^{82}$.

Sin embargo, en casos posteriores de publicidad no consentida, las cortes proporcionan protección. Las cortes reconocen el derecho a la propia imagen y la propiedad sobre

72 Diaz Castaño con Diario La Cuarta (1993) C 4.

73 Díaz Castaño con Diario La Cuarta (1993) C 5.

74 Rischmaui Grinblatt con COPESA S.A. (1997) C 4.

75 Rischmaui Grinblatt con COPESA S.A. (1997) C 5.

76 Cohen Sabah con Diario La Tercera (2000) C 4.

77 Ustovic Kaflik con Sáez Infante (2002) C 2.

78 No está disponible dicha sentencia.

79 Caszely Garrido con Salo Editores (1982) C $\mathrm{C}^{\circ} 3$.

80 Caszely Garrido con Salo Editores (1982) C $\mathrm{C}^{\circ} 3$.

81 Caszely Garrido con Salo Editores (1982) C $\mathrm{C}^{\circ} 3$.

82 Caszely Garrido con Salo Editores (1982) C 4. 
ella ${ }^{83}$, o declaran que existe un derecho a la propia imagen que es parte del derecho a la privacidad $^{84}$.

2.3.7. Distorsión. Esta categoría consiste en diseminar cierto tipo de información o hacerlo de cierto modo que conduce a equívoco y afecta la manera como los demás perciben a una persona ${ }^{85}$. En esta categoría se encontraron varios casos que es posible agrupar en varias secciones:

i) Casos de campañas de publicidad relativas a las drogas o la violencia. Existen tres casos de campañas de publicidad impulsadas por una municipalidad y Conace para prevenir la violencia y el uso de drogas. Las campañas están amparadas en un fin de utilidad pública. En esos casos, las entidades elaboraron y distribuyeron afiches, en los cuales aparecía la imagen de una persona, que fue utilizada sin su consentimiento. En el primer caso, se trata de un afiche que mostraba una niña con cara triste, junto a una leyenda que decía: "Cuando sea grande ... no quiero maltratar a mi familia". La Corte de Apelaciones rechaza la acción porque el afiche no le atribuye a la familia ninguna conducta maltratadora ${ }^{86}$. Además, la corte estima que no se vulnera la honra porque la campaña tiene fines altruistas y no ha habido intención de ofender ${ }^{87}$. La Corte Suprema revoca la sentencia y acoge el recurso de protección estimando que el afiche sí es lesivo para la niña y su familia porque hace aparecer a la menor como víctima de violencia ${ }^{88}$.

En los dos casos posteriores, las cortes acogieron los recursos protección ${ }^{89}$ porque la fotografía: “...induce a creer que la niña mostrada allí ha sido o podría ser víctima del flagelo de la droga" 90 .

ii) Casos de reportajes sobre drogas o hechos privados. Un caso se refiere a Televisión Nacional de Chile, que realizó un reportaje sobre la droga Éxtasis en el programa Enlaces, el cual se encuentra disponible en su sitio web. En dicho sitio, aparecen varias fotografías, entre ellas, la de la recurrente, quien estima que se la expone ante el mundo como una drogadicta, vulnerando la vida privada y la honra. La Corte de Apelaciones acoge el recurso, por estimar que el reportaje produce una asociación entre la recurrente y las drogas, causándole un daño ${ }^{91}$. Además, la corte declara que el reportaje daña la privacidad, la reputación y el derecho a la propia imagen ${ }^{92}$. Otro caso, ya visto en otra categoría, se refiere al reportaje sobre el accidente de avión en Arequipa, que ahonda en el suicidio del padre de

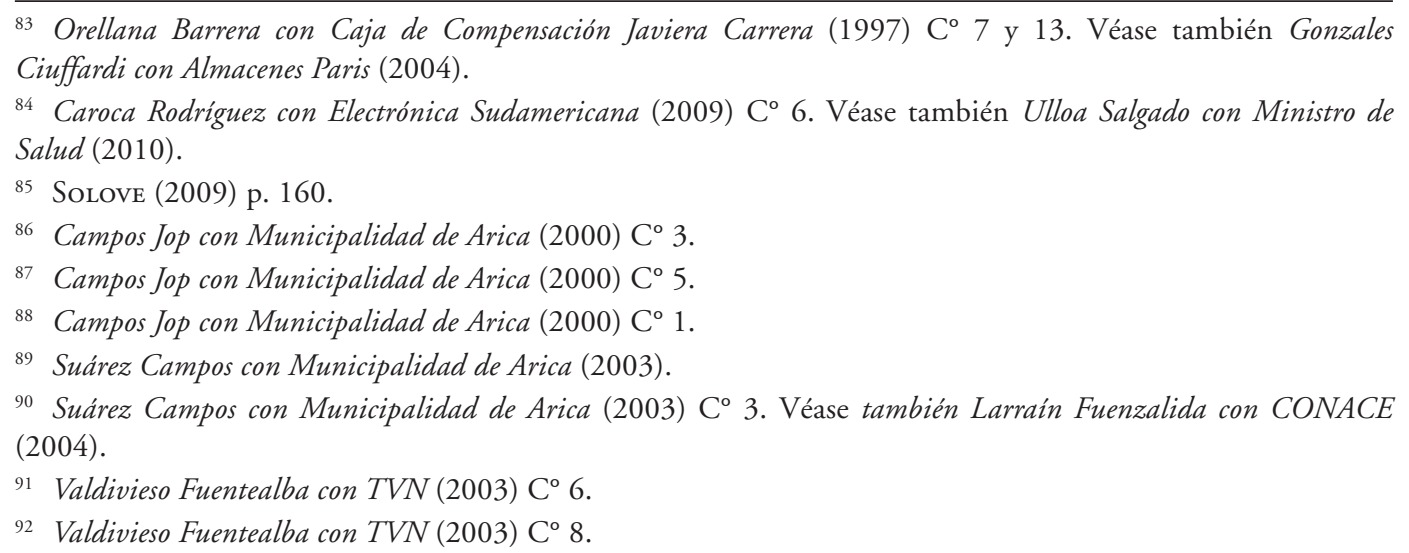


una de las víctimas del accidente. La Corte de Apelaciones acoge el recurso, estimando que la conexión entre el suicidio del padre y el accidente y muerte de la hija puede ser inapropiada ${ }^{93}$, aunque la Corte Suprema rechaza el recurso, como ya se explicó.

iii) Insertos o publicaciones en diarios. En un caso, una concejala de Tocopilla recurre de protección en contra del diario El Polémico, por una crónica en la cual se alude a un viaje a Paraguay que ella habría realizado con el alcalde, supuesto enemigo político, viaje realizado en calidad de autoridades comunales y con recursos municipales, indicando que el viaje parece luna de miel, publicando una foto de una pareja desnuda, cuyos rostros fueron sustituidos por los de la concejala y el alcalde, y adjuntando una frase sugerente: "Tocopillanos a la Paraguaya”. La corte rechaza el recurso porque valida el uso de la sátira y la crítica a autoridades públicas ${ }^{94}$ y porque la crónica no se refiere hechos de la vida privada ${ }^{95}$. En otro caso, el recurrente interpone una acción de protección en contra de la empresa que lo despidió porque publicó un inserto en un periódico en el cual señala que el recurrente había dejado de pertenecer a esa empresa y agregaba la frase: "Se nos hace un deber comunicarles que no nos responsabilizamos de ningún acto que este señor pudiere efectuar a nombre de nuestra empresa". La corte rechaza el recurso porque una parte del aviso es verídica y no hay crítica al empleado ${ }^{96}$. Sin embargo, la corte objeta la segunda parte del aviso, “...porque en alguna medida con ello se ve afectada la imagen del recurrente, suponiendo como factible que este pudiese realizar algún acto irregular..." ${ }^{97}$ De todos modos, la corte rechaza el recurso. La Corte Suprema confirmó la sentencia.

En otro caso, el recurrente interpone un recurso en contra del diario La Tercera por publicar una nota que lo individualiza como operador de un partido político y que está vinculado a denuncias por mal uso de dineros. El afectado quiso hacer uso de su derecho de rectificación, solicitó al referido diario publicar una aclaración de su autoría, ante lo cual el diario se negó. La corte acoge el recurso, señalando que se vulnera el artículo 19 n 12 y $24^{98}$. La sentencia es confirmada por la Corte Suprema.

Finalmente, está el caso de un periódico de la ciudad de Puerto Montt que informa que en el liceo de niñas existen 90 alumnas embarazadas y desarrolla un reportaje indicando que, en general, el número de embarazos adolescentes en la ciudad es superior al resto del país. Los recurrentes señalan que no es efectivo que existan 90 alumnas embarazadas sino 20, que esta revelación del periódico es falsa y agraviante, y que vulnera el derecho a la vida privada y la honra de las alumnas. La corte rechaza el recurso porque no se puede coartar la libertad de información; porque el colegio ha dado la oportunidad a las autoridades del mismo y apoderados de publicar cartas aclaratorias, y porque existen otras vías de reparación. Lo que es relevante dice relación con la forma de entender el derecho a la privacidad: la corte señala que las alumnas embarazadas no han sido individualizadas, de

\footnotetext{
93 Donoso Arteaga con Revista Caras (1998) C ${ }^{\circ} 6$.

94 Delgado Ramírez con Diario El Polémico (2007) C 5.

95 Delgado Ramírez con Diario El Polémico (2007) C 6.

96 Muñoz Parra con Sociedad Técnica de Fijación LTDA.(1985) C 4.

${ }^{7}$ Muñoz Parra con Sociedad Técnica de Fijación LTDA.(1985) C 5.

98 Salazar con Diario La Tercera (2007) C 11-12.
} 
modo que no se vulnera el derecho ${ }^{99}$. Además, añade que el error no llega al extremo de ser agraviante ${ }^{100}$. Junto con ello, la corte alude el tema del embarazo y señala que no puede considerarse deshonroso ni estigmatizante ${ }^{101}$.

iv) Otros casos. En esta parte se alude a otros casos de supuesta falsa luz, como el caso de una teleserie, una película, un concurso en una institución, una redestinación municipal y un procedimiento policial. En un caso, el recurrente acciona contra Televisión Nacional de Chile porque está transmitiendo una teleserie denominada Torre 10, en la cual aparece un abogado que opera sin mayores principios. El problema es que el personaje tiene su mismo nombre y también es abogado. Estas coincidencias le causan un perjuicio en su honra. La Corte de Apelaciones rechaza la acción, estimando que la teleserie no daña la honra del recurrente porque la coincidencia entre el personaje y el recurrente es acciden$\mathrm{tal}^{102}$. Además, porque al final de cada capítulo se transmite una leyenda que dice “...toda circunstancia o alcance de nombres con personas vivas o muertas que figuren en esta historia es solo coincidencia y no tiene relación con la realidad"103. Finalmente, porque no es posible confundir un personaje ficticio e imaginario con el recurrente ${ }^{104}$.

En otro caso, un grupo de abogados interpone un recurso de protección en contra del Consejo de Calificación Cinematográfica por haber autorizado la exhibición de la película "La Última Tentación de Cristo". Estiman que dicha película afecta la honra de Cristo, de las personas que creen en él y de la Iglesia Católica. La Corte de Apelaciones acoge el recurso estimando que la película daña la honra de Cristo por la forma como él aparece retratado ${ }^{105}$. Se señala que la imagen de Cristo se aparta de la realidad; es una imagen que degrada a Cristo ante todos quienes creen en él; es una imagen absurda. La Corte Suprema confirma la decisión, apoyando la idea de que la película presenta una imagen distorsionada ${ }^{106}$.

En otra situación, una persona recurre en contra de la Cooperativa de Ahorro y Crédito Oriente por haberle negado el derecho a participar en la elección del Consejo de Administración estimando que no cumplía con el requisito de tener "antecedentes intachables”. El recurrente estima que esta consideración es falsa e injuriosa y vulnera su derecho a la honra, entre otros derechos. La Corte de Apelaciones estima que la referida calificación es arbitraria y acoge el recurso por vulnerar honor, su buena fama, el buen crédito, su prestigio y reputación ${ }^{107}$.

En otro caso, el director de un liceo recurre en contra del Departamento de Administración de la Educación Municipal de Recoleta por haberlo redestinado a otro establecimiento más pequeño, rebajándolo de grado y de sueldo, y colocándolo en una situación sin ninguna proyección profesional. La Corte de Apelaciones rechaza el recurso porque

\footnotetext{
99 Centro de Padres Liceo Isidora Zegers con Diario El Llanquihue (2005) Co 7.

100 Centro de Padres Liceo Isidora Zegers con Diario El Llanquihue (2005) C 5.

101 Centro de Padres Liceo Isidora Zegers con Diario El Llanquihue (2005) C 8.

102 Walker Cerda con TVN (1984) $\mathrm{C}^{\circ} 3$.

103 Walker Cerda con TVN (1984) $\mathrm{C}^{\circ} 3$.

104 Walker Cerda con TVN (1984) $\mathrm{C}^{\circ} 4$.

105 García Valdez con Consejo de Calificación Cinematográfica (1997) C 7.

106 García Valdez con Consejo de Calificación Cinematográfica (1997) C 14.

107 Sarabia Acuña con ORIENCOOP (2009) C 13.
} 
estima que la redestinación no es arbitraria ni ilegal y porque no afecta ningún derecho constitucional $^{108}$. La Corte Suprema revoca la decisión, estimando que los deméritos que se imputan al docente no han sido establecidos fehacientemente ${ }^{109}$ y deja sin efecto la medida de traslado.

En otra ocasión, una señora recurre en contra de la Policía de Investigaciones pues algunos funcionarios se dirigieron a su lugar de trabajo en el Banco Estado, exhibieron sus placas institucionales y requirieron conversar con su Jefe directo y con el jefe de operaciones del Banco, imputándole haber enviado correos electrónicos a una Subinspector, con amenazas y amedrentamientos, y acusándola de obtener un correo privado de la subteniente de la base de datos del banco, violando el secreto bancario. La Corte de Apelaciones acoge el recurso. Estima que el procedimiento observado por la policía es ilegal ${ }^{110}$ y afecta el derecho a la honra pues se ha vulnerado el patrimonio moral de la afectada ${ }^{111}$.

\subsection{INVASIÓN}

Esta es la cuarta y última dimensión de privacidad que identifica Solove. Esta dimensión comprende dos categorías: Primero, la Intrusión, que consiste en entrometerse en la soledad o reclusión de un individuo o en sus asuntos privados ${ }^{112}$. Esta sería la idea de privacidad que habrían sugerido primordialmente Warren y Brandeis ${ }^{113}$. Segundo, Interferencia Decisional, que sería la interferencia del gobierno en las decisiones de las personas relativas a ciertas materias en sus vidas ${ }^{114}$. Esta dimensión de privacidad se distingue de las anteriores en un factor que es esencial: no implica necesariamente información ${ }^{115}$.

Ahora bien, en la primera de las categorías, la Intrusión, hemos incluido los casos de revisión de correos electrónicos. Esto puede ser problemático. En algún sentido, la revisión de correspondencia privada no corresponde exactamente a Invasión, pues la invasión apunta a la idea de tranquilidad o de seclusión. En consecuencia, calzan mejor con esta categoría los casos de perturbación en el hogar y edificaciones en altura, que veremos luego. Sin embargo, entrometerse en la correspondencia privada de alguien puede provocar perturbación de su tranquilidad. Por tanto, se puede justificar incluir en esta categoría los casos de correos electrónicos. Como quiera que sea, la idea es abrir el debate en Chile sobre la mejor forma de sistematizar la jurisprudencia nacional.

2.4.1. Intrusión. Esta categoría registra muchos casos en Chile que se pueden separar en varios grupos:

i) Revisión de material privado. Existen casos de revisión de material privado como correos electrónicos, un sitio web personal, una cámara fotográfica, un computador, y un

108 Saavedra Yáñez con Departamento de Administración de Educación Recoleta (1997) C 8.

109 Saavedra Yáñez con Departamento de Administración de Educación Recoleta (1997) $\mathrm{C}^{\circ} 1$.

110 Piña Ortiz con PDI (2007) $\mathrm{C}^{\circ} 7$.

111 Piña Ortiz con PDI (2007) C 11.

112 Solove (2009) p. 162.

113 Warren y Brandeis (1890) pp. 193-220.

114 Solove (2009) p. 166.

115 Solove (2009) p. 161. 
caso de investigación. En el caso de correos electrónicos, un grupo de funcionarios del MOP recurre en contra de la Ministra Chevesich porque ha dispuesto la revisión de todos los correos de la unidad de concesiones, de un largo período de tiempo, sin distinguir correos laborales de privados, o si los titulares estaban siendo investigados o no. La Corte de Apelaciones rechaza el recurso estimando que no se ve vulnerado el derecho a la privacidad. Primero, porque la Constitución permite acceder a correspondencia privada en los casos previstos por la ley, como es el caso de investigación judicial ${ }^{116}$. Segundo, porque la forma de acceder a la información estaba justificada en virtud de las medidas de protección adoptadas por la recurrida ${ }^{117}$. Finalmente, porque la información estaba consolidada de modo que era imposible determinar de antemano si el tipo de correo o el remitente o destinatario eran relevantes para la investigación; por tanto, se justificaba revisarlos todos, con las medidas de protección señaladas ${ }^{118}$.

En otro caso, se recurre contra un colegio por haber expulsado a un alumno que subió a su fotolog personal en internet una imagen modelada computacionalmente que muestra a dos profesores del establecimiento en una posición embarazosa. El colegio tuvo acceso al fotolog del alumno sin su autorización. La corte rechaza el recurso porque estima que la medida de expulsión está justificada, atendidas las faltas previas cometidas por el alumno ${ }^{119}$. La corte no se preocupa especialmente por la privacidad del fotolog.

Otro caso afecta a una alumna que es expulsada del colegio porque en su cámara fotográfica se encontró material que el colegio califica de pornográfico. La Corte de Apelaciones acoge la acción por violación de privacidad, por faltas al debido proceso y por otros derechos. En cuanto a la privacidad, la corte estima que el contenido de una máquina fotográfica es privado y no puede ser revisado por la inspectora del colegio. Añade que a lo sumo la inspectora pudo requisar la máquina y ponerla a disposición de los padres con el debido resguardo de los datos y en ningún caso enterarse de su contenido ${ }^{120}$. Sin embargo, la Corte Suprema revoca la sentencia, estimando que en la expulsión no se aprecia un acto arbitrario o ilegal ${ }^{121}$. El fallo presenta un voto disidente del ministro Pierry.

En un caso de tutela laboral, que se incluye de manera excepcional, una funcionaria es despedida por información privada que es encontrada en su computador. Se constata que la empresa no posee reglamentación de acceso a información privada. La corte acoge el recurso, por estimar que la información era privada y se vulneró la garantía del no $5^{122}$.

Hubo un caso de investigación intrusiva, que cabe incluir en esta sección. La Contraloría Regional de Atacama está investigando denuncias formuladas en contra de funcionarios de la Municipalidad de Copiapó. Para ese efecto, dispone la visita en terreno de fiscalizadoras, quienes proceden a tomar fotografías de los funcionarios en su lugar de trabajo. Los funcionarios afectados recurren contra la Contraloría y los fiscalizadores, alegando que

\footnotetext{
116 De la Puente Droguett con Ministra en visita (2004) Co 6 letra f.

117 De la Puente Droguett con Ministra en visita (2004) C 9.

118 De la Puente Droguett con Ministra en visita (2004) C 9.

119 Velozo Rencoret con Colegio Mayor de Peñalolén (2007) C 6 y 7.

120 Ramos Gallardo con Colegio Nuestra Señora de Loreto (2008) C 18.

121 Ramos Gallardo con Colegio Nuestra Señora de Loreto (2008) C C $^{\circ}$-3.

122 Madrid Obregon con Sociedad Profesional Kronos (2008) C 9.
} 
su conducta los pilló por sorpresa, que les dio un trato vejatorio e indigno y afectó su imagen personal, su vida privada, honra y dignidad. La Corte de Apelaciones acoge el recurso, reconociendo el derecho a la imagen ${ }^{123}$, declarando que ese derecho se tiene en cualquier lugar, sea público o privado ${ }^{124}$ y afirmando que ese derecho es parte de la vida privada ${ }^{125}$. La corte ordena que las fotografías sean eliminadas del expediente en el cual se encuentren.

ii) Casos de perturbación en el hogar. Hay tres casos de personas que son víctimas de cobranza de deudas. En uno de ellos, una persona es hostigada con llamadas a su casa, que buscan cobrar deuda del hijo. Alega que eso perturba su vida privada y su honra. La corte acoge la acción, estimando que la persona ha sido perturbada en su vida privada por llamadas telefónicas destinadas a cobrar extrajudicialmente una deuda de la que no puede ser obligada a hacerse cargo $^{126}$. La Corte Suprema confirma la sentencia. En otro caso, el afectado recibe una carta de una empresa de cobranza, citándolo a la oficina de la empresa, a fin de arreglar un asunto sobre el cual no se le entregó ningún tipo de información y bajo el apercibimiento de que si no lo hacía la empresa haría que un Ministro de Fe lo visitara y embargara todos los bienes de su domicilio. La Corte de Apelaciones acoge el recurso, estimando que en la especie existen amedrentamientos y hostigamientos para presionar al recurrente $^{127}$, lo que vulnera el derecho a la vida privada ${ }^{128}$. La sentencia es confirmada por la Corte Suprema. En cambio, en otro caso similar, ante la misma Corte de Apelaciones, el afectado recibe en su casa carta de cobranza y el anuncio de acciones judiciales. La corte rechaza el recurso porque no se ve vulnerada garantía alguna. Además, la corte declara que el acto de cobranza corresponde al legítimo ejercicio de un derecho ${ }^{129}$. La sentencia es confirmada por la Corte Suprema.

Otro caso corresponde al dueño de un departamento, que recurre en contra de la comunidad del edificio y el administrador, por haberle cortado la luz. El administrador y la comunidad del edificio adoptaron esta decisión pues estimaron que el departamento era utilizado como prostíbulo. Además, adoptaron medidas de control de ingreso, como exhibir el carnet de identidad. La corte acoge el recurso porque el corte de luz es ilegal y vulnera el derecho propiedad ${ }^{130}$. La Corte Suprema confirma la decisión. Este podría ser un caso de intrusión porque se perturbaría la tranquilidad del hogar, pero la corte no alude a la privacidad.

Otro caso corresponde a los moradores de un fundo que reclaman en contra de actividades y faenas ruidosas que se realizan en el predio vecino. Señalan que estos ruidos perturban la tranquilidad, e invocan los derechos del no 1 y 8 del artículo 19. La corte declara que las actividades extractivas que se realizan en el predio vecino infringen la ley de bases del medio ambiente y, por ende, son ilegales y arbitrarias; además, vulneran las garantías

\footnotetext{
${ }^{123}$ Mendoza Morales con Contralora Regional de Atacama (2008) C $\mathrm{C}^{\circ} 6$.

124 Mendoza Morales con Contralora Regional de Atacama (2008) $C^{\circ} 6$.

125 Mendoza Morales con Contralora Regional de Atacama (2008) C 7.

126 Ossa Valdés con SERVINCO S.A. (2009).

127 Penroz Armijo con Empresa de Cobranza Silca (1999) Co 4.

128 Penroz Armijo con Empresa de Cobranza Silca (1999) C 5.

129 Moreno Ramirez con Celis Ovalle (1996) C 3.

130 Transportes Artemio Eloy con Comunidad Edificio Bellavista ( 2009) C 12.
} 
invocadas por los recurrentes ${ }^{131}$. Como se puede advertir, el aspecto de tranquilidad que podía ser parte de la privacidad es canalizado por la corte y los recurrentes a través de la integridad psíquica del no 1 del artículo 19.

iii) Casos de edificaciones en altura. Hay varios casos de personas que recurren en contra de una edificación en altura, porque ella permitirá tener acceso visual a los predios vecinos, afectando la privacidad. En uno de ellos, se trata de un proyecto arquitectónico de conjuntos armónicos. La corte rechaza la acción por no advertir ilegalidad ni arbitrariedad en el permiso de edificación ${ }^{132}$. La Corte Suprema confirma la sentencia, aunque existe una prevención de un ministro que reconoce que la edificación en altura vulnera la privacidad y la calidad de vida de los vecinos de esa construcción ${ }^{133}$. En otro caso que es similar, la Corte de Apelaciones acoge el recurso, estimando que el permiso es ilegal y vulnera el derecho de propiedad, la privacidad y la igual ante la ley. Se infringe la privacidad porque edificios elevados permiten a terceros tener una amplia visión del interior de las viviendas ${ }^{134}$. La Corte Suprema confirma pero solo por propiedad ${ }^{135}$. Existe otro caso de edificación en altura en que se pretende aplicar normas de conjuntos armónicos. En este recurso se reconoció que la edificación en altura vulnera el derecho a la vida privada, en la medida en que los patios, terrazas, piscinas y otras dependencias, así como sus moradores, quedan expuestos ante quienes habiten en la edificación en altura ${ }^{136}$.

Cabe señalar que en estos casos, cuando la autorización municipal o permiso de edificación es declarado ilegal, se acoge el recurso, pero cuando el permiso ha sido conferido conforme con la ley, se rechaza la acción ${ }^{137}$. Esto introduce una sombra de duda sobre si la edificación en altura vulnera la privacidad o no. En este sentido, se entienden tres casos más. Uno de ellos se refiere a una ampliación de vivienda a dos pisos. Se alega que la construcción no respeta la distancia mínima, lo que permite tener acceso visual a la vivienda vecina. La corte acoge el recurso porque la edificación no respetó las normas de distancia mínima, de modo que la construcción es ilegal y afecta el derecho de propiedad ${ }^{138}$. En cambio, en otros casos se rechaza el recurso porque la construcción es legal. En uno de ellos, se trata de una mansarda que permite tener acceso visual a la casa del vecino. La mansarda está construida conforme la ley, de modo que se rechaza la acción ${ }^{139}$. En el otro se construye una ventana que permite ver el predio vecino. Se rechaza la acción porque la construcción es legal ${ }^{140}$.

\footnotetext{
131 Andueza Fouque con Inela-Latour S.A. (2004) C $\mathrm{C}^{\circ} 6$.

132 Vecinos Barrio Jardín del Este con Dirección de obras de la Municipalidad de Las Condes (1991).

133 Vecinos Barrio Jardín del Este con Dirección de obras de la Municipalidad de Las Condes (1991), prevención de Germán Valenzuela.

134 Ducci Valenzuela con Director de Obras de la Municipalidad de Vitacura (1996) C 11.

135 Ducci Valenzuela con Director de Obras de la Municipalidad de Vitacura (1996) Co 4.

136 Aninat Martinez con Director de Obras de la Municipalidad de Vitacura (1997).

137 Por ejemplo Karmy Salah con Prohabit Gestión Inmobiliaria (2002).

138 Otárola Espejo con López Alarcón (2003) C 8-9.

139 Núnez Pino con Vallarino Estay y otros (1984) confirmada por la Corte Suprema.

140 Cuneo Quijada con Dirección de Obras de la Municipalidad de Chillán (1994) confirmada por la Corte Suprema.
} 
Finalmente, tenemos el caso de camiones que llevan mercadería de supermercado y pasan por un camino a 30 centímetros de un muro medianero, de baja altura, que permitía a los choferes y otros pasajeros ver el interior de las casas. La corte acoge el recurso, señalando que se provoca una seria perturbación del derecho a la privacidad porque se puede ver al menos el patio de las viviendas ${ }^{141}$. La Corte Suprema confirma la sentencia ${ }^{142}$.

\subsubsection{Interferencia decisional. Esta categoría se refiere a la interferencia del gobierno} en las decisiones de las personas relativas a ciertas materias en sus vidas. Sin embargo, no se encontraron casos de este tipo en Chile ${ }^{143}$.

Como conclusión de esta parte se puede señalar que de las 16 categorías de privacidad que Solove sugiere distinguir, en Chile encontramos casos para casi todas ellas, salvo tres: agregación, chantaje e interferencia decisional. Dado que casi todas las categorías son aplicables, tal vez sea una buena idea comenzar a discutir sobre ellas para efectos de sistematizar y reconstruir la jurisprudencia chilena. Quizá sea útil avanzar más allá de la mera distinción entre captación y divulgación. Respecto de los tribunales, ellos parecen no advertir que casos de recolección, como la vigilancia e interrogación, puedan tener que ver con la privacidad. Lo mismo cabe decir de la identificación. En cambio, las cortes sí entienden que la inseguridad, el uso secundario y la exclusión son problemas de privacidad (y de honra). En materia de divulgación, la privacidad como confidencialidad, la revelación, la exposición y la apropiación, han sido reconocidas por las cortes y protegidas, aunque con matices. En cambio, la distorsión o falsa luz no ha sido identificada por las cortes como un asunto de privacidad, pero ha sido protegida. Finalmente, en materia de invasión, las intrusiones en la tranquilidad han sido reconocidas y protegidas por las cortes, aludiendo a la privacidad, aunque con matices.

\section{CONCLUSIONES}

1. En Chile tenemos una extensa literatura referida a la privacidad, pero escasean los trabajos destinados a sistematizar categorías de privacidad y a sistematizar la jurisprudencia. Realizar ese esfuerzo es muy relevante porque nos ayudaría a comprender con mayor agu-

141 Busta Lapostol con Supermercado UNIMARC S.A. (2001) C $\mathrm{C}^{\circ} 4$.

${ }_{142}$ Busta Lapostol con Supermercado UNIMARC S.A. (2001).

143 En Chile ha habido casos que, desde la perspectiva estadounidense y su jurisprudencia (Griswold v. Connecticut, 381 U.S. 479 [1965]) se pueden relacionar con esta dimensión de la privacidad como autonomía y no interferencia. Por ejemplo, en los casos de Testigos de Jehová las cortes ordenan la transfusión de sangre contra la voluntad de la persona, con dos excepciones (Kong Urbina con Leuquen Tolosa (2008) y Clínica Antofagasta con Bonifaz (2008)) en las cuales las cortes acogieron el argumento de la autonomía. También se pueden citar los casos de huelgas de hambre, en los cuales las cortes ordenan la intervención forzada sobre el huelguista. Por tanto, se afecta en estos casos la autonomía. Sin embargo, la jurisprudencia no ha visto estos casos como casos que involucran el derecho a la privacidad, ni siquiera en los dos casos mencionados en que reconoce la autonomía. Los afectados tampoco han entendido que se ha afectado su derecho a la privacidad. La explicación es que la noción anglosajona de privacidad como autonomía parece no tener raigambre en la tradición continental. Por otra parte, en la doctrina nacional tampoco es pacífica esa noción de privacidad. Por tanto, se ha decidido no incluir esos tipos de casos en este trabajo de sistematización de la jurisprudencia nacional. 
deza en qué consiste el derecho a la vida privada y eso podría proporcionar criterios para que las cortes puedan resolver de mejor manera los casos que se le presenten.

2. Se exceptúan de lo anterior los trabajos señores Rodríguez ${ }^{144}$, Gómez $^{145}$, Angui$\operatorname{ta}^{146}$ y Tapia ${ }^{147}$. El presente trabajo propone continuar con ese esfuerzo, incorporando nuevas categorías de privacidad sugeridas por Solove.

3. Una visión más compleja de privacidad permite exceder la mera distinción entre captación y divulgación. Es posible que haciendo mayores distinciones podamos apreciar de mejor manera las hipótesis de daños que se pueden infligir al derecho a la privacidad. No es necesario adherir a todas las categorías que sugiere el autor americano, pero al menos vale la pena discutirlas y aplicarlas a los casos producidos en Chile para ver si podemos entenderlos mejor.

\section{BIBLIOGRAFÍA CITADA}

Anguita, Pedro (2006): "Jurisprudencia Constitucional sobre el Derecho a la propia Imagen y la Vida Privada en Chile (1981-2004): un intento de sistematización” en: GonzÁLez, Felipe (ed), Libertad de Expresión en Chile (Facultad de Derecho, Universidad Diego Portales, Santiago) pp. 319-521.

Barros, Enrique (1998): "Honra, privacidad e información: un crucial conflicto de bienes jurídicos", Revista de Derecho, Universidad Católica del Norte, año 5: pp. 45-58.

Corral Hernán (2000): “Configuración Jurídica del Derecho a la Privacidad. II: Concepto y delimitación” Revista Chilena de Derecho, Vol. 27, N²: pp. 331-355.

Gómez Gastón (2005): Derechos Fundamentales y Recurso de Protección (Ed. Universidad Diego Portales, Santiago) 665 p.

Rodríguez, María (1999): "Protección de la Vida Privada: Líneas Jurisprudenciales", Revista Chilena de Derecho, Vol. 26 No 3: pp. 719-744.

Solove, Daniel J. (2006): "A Taxonomy of Privacy", University of Pennsylvania Law Review. vol. 154, No 3: pp. 478-564.

Solove, Daniel J. (2009): Understanding Privacy (Harvard University Press) 257 pp.

TAPia Mauricio (2008): "Fronteras de la vida privada en el derecho chileno", Revista Chilena de Derecho Privado, No 11: pp. 117-144.

Warren, Samuel D. y Brandeis, Louis D. (1890): “The Right to Privacy”, Harvard Law Review, Vol. IV, December, No 5: pp. 193-220.

\section{JURISPRUDENCIA CITADA}

Bart Vega con Inspección Provincial del Trabajo IX Región (2009): Corte Suprema, 3 de junio de 2009 (Recurso de Protección), Rol N²455-2009.

\footnotetext{
144 Rodríguez (1999).

145 Gómez (2005).

146 Anguita (2006).

147 Tapia (2008).
} 
Vázquez Torres con Empresas Aqua Chile (2006): Corte Suprema, 5 de enero de 2006 (Recurso de Protección), MicrojurisID: MJCH_MJJ17665/RDJ17665.

Sociedad Industrial y Comercial Salucorp LTDA con Dirección del Trabajo Santiago Oriente (2009): Corte Suprema, 11 de febrero de 2009 (Recurso de Protección), MicrojurisID: MJCHMJJ19395.

Phillips Salinas con Alcalde de la Municipalidad de El Bosque (2002): Corte de Apelaciones de San Miguel, 9 de diciembre de 2002 (Recurso de Protección), IDLegalPublishing: 30512.

Fuentes Castro con Alcaide Centro Penitenciario Punta de Peuco (2007): Corte de Apelaciones de Santiago, 9 de abril de 2007 (Recurso de Protección), MicrojurisID: MJCH_ MJj9558.

Sindicato de Trabajadores $N^{\circ} 1$ del Banco de Chile S.A. con Banco de Chile S.A. (2004): Corte de Apelaciones de Santiago, 15 de enero de 2004 (Recurso de Protección), IDLegalPublishing: 30039.

Sindicato de Trabajadores $N^{\circ} 1$ del Banco de Chile S.A. con Banco de Chile S.A. (2004): Corte Suprema, 13 de abril de 2004 (Recurso de Protección), IDLegalPublishing: 30039.

Valparaíso Stores Co. S.A. con Inspección Comunal del Trabajo de Valparaíso (2009): Corte de Apelaciones de Valparaíso, 4 de septiembre de 2008 (Recurso de Protección), IDLegalPublishing: 41603.

Valparaíso Stores Co. S.A. con Inspección Comunal del Trabajo de Valparaiso (2009): Corte Suprema, 26 de enero de 2009 (Recurso de Protección), IDLegalPublishing: 41603.

Sename con Juez del Juzgado de Garantía de Talca (2005): Corte de Apelaciones de Talca, 20 de septiembre de 2005 (Recurso de Protección), IDLegalPublishing: 33081.

Sename con Juez del Juzgado de Garantía de Talca (2005): Corte Suprema, 27 de octubre de 2005 (Recurso de Protección), IDLegalPublishing: 33081.

Retamales Saldias y otros con Sename (2009): Corte de Apelaciones de Santiago, 22 de abril de 2009 (Recurso de Protección), Rol 11479-2008 (Tomada del expediente).

CTC con Subsecretario de Telecomunicaciones (1995): Corte de Apelaciones de Santiago, 1 de junio de 1995 (Recurso de Protección), Rol No 1105-1995 Gaceta Jurídica N¹81, pág. 43-45.

Asociación de Funcionarios del Hospital Base de Valdivia con Contralor de la Región de Los Lagos (2006): Corte de Apelaciones de Puerto Montt, 13 de abril de 2006 (Recurso de Protección), IDLegalPublishing: 34516.

Salazar Leiva con MOP (2009): Corte de Apelaciones de Puerto Montt, 22 de septiembre de 2009 (Recurso de Protección), IDLegalPublishing: 43033.

Salazar Leiva con MOP (2009): Corte Suprema, 7 de Diciembre de 2009 (Recurso de Protección), IDLegalPublishing: 43033.

Troncoso Huerta con Fondo Nacional de Salud Antofagasta (1986): Corte de Apelaciones de Antofagasta, 29 de agosto de 1986 (Recuso de Protección), MicrojurisID: MJCH_ MJJ5189.

Troncoso Huerta con Fondo Nacional de Salud Antofagasta (1986): Corte Suprema, 6 de noviembre de 1986 (Recuso de Protección), MicrojurisID: MJCH_MJJ5189. 
Caro Marambio con Fondo Nacional de Salud Valparaiso (2005): Corte de Apelaciones de Valparaíso, 8 de noviembre de 2005 (Recurso de Protección), IDLegalPublishing: 33120.

Muller Pasmiño con Babaic Bartulovic (2006): Corte Suprema, 4 de enero de 2006 (Recurso de Protección), MicrojurisID: MJCH_MJJ9540.

Anguita Ramírez con Juez Titular del Familia de Viña del Mar (2008): Corte Suprema, 11 de septiembre de 2008, IDLegalPublishing: 39829.

Aguilar Cáceres con UNIACC (2007): Corte de Apelaciones de Santiago, 15 de junio de 2007 (Recurso de Protección), IDLegalPublishing: 36762.

Luksic Craig con Martorell Camarella (1993): Corte Suprema, 15 de junio de 1993 (Recurso de Protección), MicrojurisID: MJCH_MJJ2366.

Bohme Bascuñán con Clínica Alemana (1992): Corte de Apelaciones de Santiago, 17 de noviembre de 1992 (Recurso de Protección), Revista de Derecho y Jurisprudencia, Tomo 89 (1992), III, Sección 5.

Narváez Muñoz con Director de Liceo Politécnico C-40 Villarrica (2009): Corte de Apelaciones de Temuco, 1 de marzo de 2010 (Recurso de Protección), Rol No 1603-2009.

Callejas Leiva con Echeverría Yáñez (2000): Corte de Apelaciones de Santiago, 31 de octubre 2000 (Recurso de Protección), IDLegalPublishing: 18113.

Ferrer Lagunas con Levi (1993): Corte Suprema, 13 de abril de 1993 (Recurso de Protección), IDLegalPublishing: 12218.

Torres Hevia con TVN (2003): Corte de Apelaciones de Santiago, 30 de septiembre de 2003 (Recurso de Protección), IDLegalPublishing: 28839.

Briceño Echeverría con Corporación Administrativa del Poder Judicial (2001): Corte de Apelaciones de Santiago, 1 de junio de 2001 (Recurso de Protección), IDLegalPublishing: 22293

Vizcarra Ramírez con Jueces del Tribunal Oral en lo penal de Coyhaique (2004): Corte de Apelaciones de Coyhaique, 26 de enero de 2004 (Recurso de Protección), IDLegalPublishing: 29754.

Alvarado Solari con Diario La Cuarta (1989): Corte de Apelaciones de Santiago, 1 de agosto de 1989 (Recurso de Protección), MicrojurisID: MJCH_MJJ4550.

Díaz Castaño con Diario La Cuarta (1993): Corte de Apelaciones de Santiago, 26 de abril de 1993 (Recurso de Protección), IDLegalPublishing: 20157.

Rischmaui Grinblatt con COPESA S.A. (1997): Corte de Apelaciones de Santiago, 8 de septiembre de 1997 (Recurso de Protección), Revista de Derecho y Jurisprudencia, Tomo 114 (1997), $N^{\circ}$ 3, Sección 5.

Cohen Sabah con Diario La Tercera (2000): Corte de Apelaciones de Santiago, 26 de enero de 2000 (Recurso de Protección), Rol 5595-1999.

Ustovic Kaflik con Sáez Infante (2002): Corte de Apelaciones de Temuco, 6 de diciembre de 2002 (Recurso de Protección), Rol 595-2001.

Caszely Garrido con Salo Editores (1982): Corte Suprema, 18 de agosto de 1982 (Recurso de Protección), MicrojurisID: MJCH_MJJ5958. 
Orellana Barrera con Caja de Compensación Javiera Carrera (1997): Corte de Apelaciones de Valparaíso, 27 de marzo de 1997 (Recurso de Protección), MicrojurisID: MJCH_ MJJ1390.

Gonzales Ciuffardi con Almacenes Paris (2004): Corte de Apelaciones de Santiago, 16 de noviembre de 2004 (Recurso de Protección) Rol 6357- 2004 (Tomada del Expediente).

Caroca Rodríguez con Electrónica Sudamericana (2009): Corte Suprema, 9 de junio de 2009 (Recurso de Protección), MicrojurisID: MJCH_MJJ20544.

Ulloa Salgado con Ministro de Salud (2010): Corte de Apelaciones de Temuco, 5 de marzo de 2010 (Recurso de Protección) Rol 35-2010 (Tomada del expediente).

Campos Jop con Municipalidad de Arica (2000): Corte de Apelaciones de Arica, 7 de julio de 2000 (Recurso de Protección), Gaceta Jurídica Vol. 242, pag.65-69, Rol 6980-2000.

Campos Jop con Municipalidad de Arica (2000): Corte Suprema, de agosto de 2000 (Recurso de Protección), Gaceta Jurídica Vol. 242, pag.65- 69, Rol 2373- 2000.

Suarez Campos con Municipalidad de Arica (2003): Corte de Apelaciones de Arica, 26 de agosto de 2003 (Recurso de Protección), Rol 9054-2003 (Tomada del Expediente).

Larraín Fuenzalida con CONACE (2004): Corte Suprema, 25 de noviembre de 2004 (Recurso de Protección), IDLegalPublishing: 31406.

Valdivieso Fuentealba con TVN (2003): Corte de Apelaciones de Santiago, 29 de enero de 2003 (Recurso de Protección), Rol 6348-2002.

Donoso Arteaga con Revista Caras (1998): Corte de Apelaciones de Santiago, 10 de agosto de 1998 (Recurso de Protección), IDLegalPublishing: 29359.

Delgado Ramírez con Diario El Polémico (2007): Corte de Apelaciones de Antofagasta, 3 de septiembre de 2007, IDLegalPublishing: 37091.

Muñoz Parra con Sociedad Técnica de Fijación LTDA.(1985): Corte de Apelaciones de Santiago, 21 de enero de 1985 (Recurso de Protección), MicrojurisID: MJCH_MJJ5320.

Salazar con Diario La Tercera (2007): Corte de Apelaciones de Santiago, 24 de enero de 2007 (Recurso de Protección), IDLegalPublishing: 35998.

Centro de Padres Liceo Isidora Zegers con Diario El Llanquihue (2005): Corte de Apelaciones de Puerto Montt, 24 de noviembre de 2005, IDLegalPublishing: 33899.

Walker Cerda con TVN (1984): Corte de Apelaciones de Santiago, 12 de septiembre de 1984 (Recurso de Protección), MicrojurisID: MJCH_MJJ5667.

García Valdez con Consejo de Calificación Cinematográfica (1997): Corte de Apelaciones, (Sin fecha)(Recurso de Protección), MicrojurisID: MJCH_MJJ67.

García Valdez con Consejo de Calificación Cinematográfica (1997): Corte Suprema, 17 de junio de 1997 (Recurso de Protección), MicrojurisID: MJCH_MJJ67.

Sarabia Acuña con ORIENCOOP (2009): Corte de Apelaciones de Talca, 18 de mayo de 2009 (Recurso de Protección), Rol 190-2009 (Tomada del Expediente).

Saavedra Yáñez con Departamento de Administración de Educación Recoleta (1997): Corte de Apelaciones de Santiago, 2 de julio de 1997 (Recurso de Protección), IDLegalPublishing: 14755.

Saavedra Yáñez con Departamento de Administración de Educación Recoleta (1997): Corte Suprema, 3 de septiembre de 1997 (recurso de protección) IDLegalPublishing: 14755. 
Piña Ortiz con PDI (2007): Corte de Apelaciones de La Serena, 21 de noviembre de 2007 (Recurso de Protección), MicrojurisID: MJCH_MJJ16207.

De la Puente Droguett con Ministra en visita (2004): Corte de Apelaciones de Santiago, 6 de diciembre de 2004 (Recurso de Protección), Rol 15260- 2004.

Velozo Rencoret con Colegio Mayor de Peñalolén (2007): Corte de Apelaciones de Santiago, 1 de marzo de 2007 (Recurso de Protección), MicrojurisID: MJCH_MJJ9242.

Ramos Gallardo con Colegio Nuestra Señora de Loreto (2008): Corte de Apelaciones de Santiago, 31 de junio de 2008 (Recurso de Protección), Rol 3620-2008 (Tomada del Expediente).

Ramos Gallardo con Colegio Nuestra Señora de Loreto (2008): Corte Suprema, 4 de diciembre de 2008 (Recurso de Protección), Rol 4877-2008 (Tomada del Expediente).

Madrid Obregon con Sociedad Profesional Kronos (2008): Juzgado de Letras del Trabajo de Copiapó, 15 de septiembre de 2008 (Tutela Laboral), MicrojurisID: MJCH_MJJ18535.

Mendoza Morales con Contralora Regional de Atacama (2008): Corte de Apelaciones de Copiapó, 12 de junio de 2008 (Recurso de Protección), MicrojurisID: MJCH_MJJ7775.

Ossa Valdés con SERVINCO S.A. (2009): Corte de Apelaciones de Santiago, 6 de enero de 2009 (Recurso de Protección), Rol 8755-2008 (Tomada del Expediente).

Penroz Armijo con Empresa de Cobranza Silca (1999): Corte de Apelaciones de Rancagua, 17 de mayo de 1999, Gaceta Jurídica 228, pág. 25 -27.

Moreno Ramírez con Celis Ovalle (1996): Corte de Apelaciones de Rancagua, 30 de agosto de 1996 (Recurso de Protección), IDLegalPublishing: 14070.

Transportes Artemio Eloy con Comunidad Edificio Bellavista (2009): Corte de Apelaciones de Santiago, 6 de noviembre de 2009 (Recurso de Protección), IDLegalPublishing: 43151.

Andueza Fouque con Inela-Latour S.A. (2004):, Corte de Apelaciones de Valdivia, 3 de junio de 2004 (Recurso de Protección), Rol 15041- 2003 (Tomada del Expediente).

Vecinos Barrio Jardín del Este con Dirección de obras de la Municipalidad de Las Condes (1991): Corte de Apelaciones de Santiago, 5 de septiembre de 1991 (Recurso de Protección), MicrojurisID: MJCH_MJJ2718.

Ducci Valenzuela con Director de Obras de la Municipalidad de Vitacura (1996): Corte de Apelaciones de Santiago (sin fecha), MicrojurisID: $M J C H \_M J J 318$.

Ducci Valenzuela con Director de Obras de la Municipalidad de Vitacura (1996): Corte Suprema, 3 de abril de 1996, MicrojurisID: MJCH_MJJ318.

Aninat Martinez con Director de Obras de la Municipalidad de Vitacura (1997): Corte Suprema, 25 de junio de 1997, MicrojurisID: MJCH_MJJ69.

Karmy Salah con Prohabit Gestión Inmobiliaria (2002): Corte de Apelaciones de Valparaíso, 8 de noviembre de 2002 (Recurso de Protección), IDLegalPublishing: 29415.

Otárola Espejo con López Alarcón (2003): Corte de Apelaciones de Concepción, 18 de noviembre de 2003 (Recurso de Protección), IDLegalPublishing: 29668.

Núñez Pino con Vallarino Estay y otros (1984): Corte de Apelaciones de Santiago, 26 de diciembre de 1984 (Recurso de Protección), MicrojurisID:MJCH_MJJ5304.

Cuneo Quijada con Dirección de Obras de la Municipalidad de Chillan (1994): Corte de Apelaciones de Chillán, 2 de mayo de 1994 (Recurso de Protección), IDLegalPublishing: 12917. 
Busta Lapostol con Supermercado UNIMARC S.A. (2001): Corte de Apelaciones de Rancagua, 21 de marzo de 2001 (Recurso de Protección), IDLegalPublishing: 18393.

Busta Lapostol con Supermercado UNIMARC S.A. (2001): Corte Suprema, 19 de marzo de 2001 (Recurso de Protección), IDLegalPublishing: 18393. 
